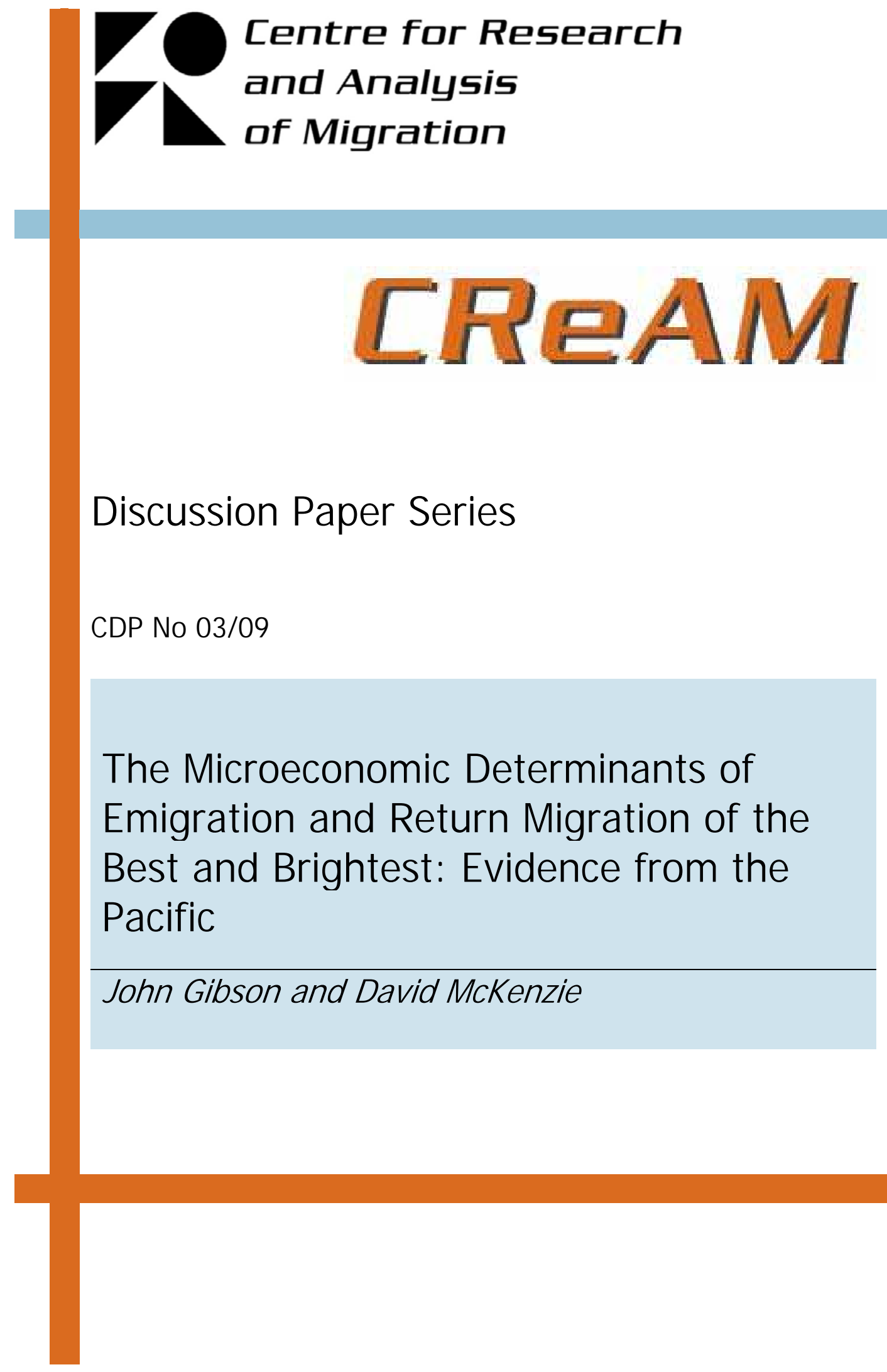




\title{
The Microeconomic Determinants of Emigration and Return Migration of the Best and Brightest: Evidence from the Pacific
}

\author{
John Gibsont and David McKenzie*
}

$\dagger$ University of Waikato and CGD

* World Bank, BREAD, CReAM, and IZA

Non-Technical Abstract

A unique survey which tracks worldwide the best and brightest academic performers from three Pacific countries is used to assess the extent of emigration and return migration among the very highly skilled, and to analyze, at the microeconomic level, the determinants of these migration choices. Although we estimate that the income gains from migration are very large, not everyone migrates and many return. Within this group of highly skilled individuals the emigration decision is found to be most strongly associated with preference variables such as risk aversion, patience, and choice of subjects in secondary school, and not strongly linked to either liquidity constraints or to the gain in income to be had from migrating. Likewise, the decision to return is strongly linked to family and lifestyle reasons, rather than to the income opportunities in different countries. Overall the data show a relatively limited role for income maximization in distinguishing migration propensities among the very highly skilled, and a need to pay more attention to other components of the utility maximization decision.

Keywords: Brain Drain, Brain Gain, Highly Skilled Migration, Return Migration, Selectivity.

JEL Classification: 015, F22, J61. 


\title{
The Microeconomic Determinants of Emigration and Return Migration of the Best and Brightest: Evidence from the Pacific ${ }^{\#}$
}

\author{
John Gibson, University of Waikato and CGD \\ David McKenzie, World Bank, BREAD, CReAM, and IZA.*
}

\begin{abstract}
A unique survey which tracks worldwide the best and brightest academic performers from three Pacific countries is used to assess the extent of emigration and return migration among the very highly skilled, and to analyze, at the microeconomic level, the determinants of these migration choices. Although we estimate that the income gains from migration are very large, not everyone migrates and many return. Within this group of highly skilled individuals the emigration decision is found to be most strongly associated with preference variables such as risk aversion, patience, and choice of subjects in secondary school, and not strongly linked to either liquidity constraints or to the gain in income to be had from migrating. Likewise, the decision to return is strongly linked to family and lifestyle reasons, rather than to the income opportunities in different countries. Overall the data show a relatively limited role for income maximization in distinguishing migration propensities among the very highly skilled, and a need to pay more attention to other components of the utility maximization decision.
\end{abstract}

Keywords: Brain Drain; Brain Gain; Highly Skilled Migration; Return Migration; Selectivity.

JEL codes: O15, F22, J61.

\footnotetext{
\# We thank the World Bank's Research Support Budget and the Center for Global Development for research funding for this project; the New Zealand Ministry of Education, New Zealand Mathematical and Chemistry Olympiad Committees for help in assembling the New Zealand sample frames; 'Alisi Katoanga for excellent fieldwork for the Tongan sample frame; Geua Boe-Gibson and Tanorama for PNG; Cristina Tealdi and Chris Hector for research assistance; and Moses Shayo, seminar participants at the Paris School of Economics and at the Globalization and the Brain Drain conference for useful comments. All views are of course those of the authors alone, and do not necessarily represent those of their employers, or the collaborating organizations.

*Corresponding author: E-mail: dmckenzie@worldbank.org.
} 


\section{Introduction}

Brain drain has long been one of the most common concerns developing countries have about migration. This concern has been amplified in recent years by the rapid increase in skilled emigration, driven in large part by developed countries shifting to more skill-intensive immigration systems. There is a long, mostly theoretical, literature on the consequences of brain drain for developing countries, with recent literature also pointing to the possibility of "brain gain” from highly skilled emigration through impacts such as an increase in the incentives to acquire human capital, remittances sent home, and return migration ${ }^{1}$. There is much less research on the determinants of the brain drain. Portes (1976) asked the central research question which has so far not been addressed. He wrote (p. 490) "given the... attractions of emigration, the real question is often not why some professionals migrate but why so few in fact leave”.

Several recent papers have looked at the macroeconomic determinants of why the level of brain drain varies across countries (Docquier, Lohest and Marfouk, 2007; Belot and Hatton, 2008; Beine, Docquier and Schiff, 2008). They find country size to be an important determinant, with much higher emigration levels from small states, and also consider country-level determinants such as income level, distance to major destinations, colonial origin, language, and political environment. Such analysis provides a first step towards understanding why some countries have higher brain levels than others, but does not allow us to answer the key question posed by Portes, which is at the individual level, why do some highly skilled individuals within a country leave, while others stay. Moreover, amongst those who go, why do some return?

Answering this question requires data on highly skilled individuals who stay and on the emigrants. Existing surveys consist of one group but not others, preventing this comparison being made. This paper presents evidence from new surveys designed by the authors to study the individual level microeconomic determinants of the brain drain, and the determinants of return migration among the highly skilled. Brain drain is of particular concern to small states (Beine et al. 2008). We focus our study on three small states with varying levels of development, population size, and brain drain. The three

\footnotetext{
${ }^{1}$ Recent literature reviews are also found in Kapur and McHale (2005), Commander, Kangasniemi and Winters (2004) and World Bank (2006).
} 
countries are: Tonga, population 112,000, for which Docquier and Marfouk (2005) estimate 75 percent of those with tertiary education live abroad; Papua New Guinea (PNG), population 6.3 million, with an estimated 29 percent brain drain rate; and New Zealand, population 4.1 million, which along with Ireland, has the highest rate of skilled emigration in the OECD, at $24.2 \%{ }^{2}$

In each country we have collected the names of individuals who were the highest achieving students in their country at the end of high school, for students graduating high school between 1976 and 2004. Depending on the country, these are either the top students in nationwide competitive examinations, or the students placed top in their class at the most academically prestigious schools in the country. We then tracked down these former top students, wherever in the world they currently live, and surveyed them. The surveys ask detailed questions on incomes and occupations available at home and abroad, risk aversion, discount rates, parental background, and other socioeconomic characteristics which are likely to predict migration and return. As well as economic factors, we include psychological and social factors emphasized by psychologists and sociologists. Finally, the surveys also collect more qualitative evidence on a range of different social and cultural push and pull factors.

Using these data we measure the emigration rates and return migration rates of the most academically talented individuals in each country, and examine which characteristics predict emigration and return. We find the incidence of ever migrating is very high, with 83 percent of Tongan top students, 67 percent of New Zealand top students and 37 percent of PNG top students having ever worked or studied abroad. The incidence of return migration is also high, with between one-quarter and one-third of top students in each country being return migrants.

We find that most of the highly skilled say that salaries would be higher for them overseas. However, among these individuals, the decision to migrate is found to be most strongly associated with preference variables, such as risk aversion, patience, and subjects studied in secondary school, and not strongly linked with economic variables such as liquidity constraints, the extent of the gain in income to be had from migration, or

\footnotetext{
${ }^{2}$ See OECD (2005). In comparison, Australia has less than 5\% of its tertiary educated natives abroad, and the United States has less than $1 \%$.
} 
macroeconomic factors. Likewise we find the decision to return amongst ever migrants is most strongly associated with preferences, with family and lifestyle reasons being stronger predictors of return than the extent of the income gains from migrating. We also find educational bonding to be an important reason for return of Papua New Guineans, with little subsequent re-migration after the two-year required period is completed. Overall the data support a limited role for income maximization in determining the migration decisions of the highly skilled, and a need to consider the other elements of the utility maximization problem.

The remainder of the paper is structured as follows. Section 2 describes the construction of the sample frame and the survey implementation. Section 3 analyzes the incidence of emigration and return migration among the top students. Section 4 models the determinants of ever migrating, and section 5 the determinants of return migration. Section 6 concludes.

\section{Putting Together a Sample Frame and the Survey}

To examine the determinants of highly-skilled emigrants, we need comprehensive data on both the highly skilled who migrate and those who return. Standard surveys do not provide this information. Many studies of migration use nationally representative surveys in the migrant origin country. Typically households are then asked to report on absent migrant members. Such surveys suffer two drawbacks for studying the migration of the highly skilled. First, they miss individuals who migrate with their entire households, which may be more likely for the highly skilled than the less skilled. ${ }^{3}$ Secondly, nationally representative surveys will contain few, if any, of the most highly skilled individuals from a country. Specialized surveys of immigrants in the destination country can help solve the first issue, but again will contain very few highly skilled migrants. Census microdata from both source and destinations may contain sufficient numbers of the highly skilled, but do not have enough detailed information on these individuals to examine the determinants of migration. As a result, a new specialized survey approach is needed.

\footnotetext{
${ }^{3}$ See for example McKenzie and Rapoport (2008), who find that Mexican migrants to the U.S. are more likely to have their spouse accompany them if they have more education.
} 


\subsection{Selection of Countries to Study}

The Docquier and Marfouk (2005) database reveals that the Pacific Islands have the highest brain drain rate of any region in the world. If general brain drain is to be a concern anywhere, this should be the region where this concern is greatest. We therefore focus on a selection of small island countries within the Pacific. By focusing on one region, with similar migrant destinations, we can take advantage of economies of scale in surveying emigrants, and compare neighboring countries with differing emigration options.

Within the Pacific we selected countries which provide a broad range of development levels and migration experiences, and where we had the necessary contacts to make the surveying feasible. The countries chosen, along with their population, and 2000 brain drain rates for those who entered their destination country after age 18 are ${ }^{4}$ :

- Tonga:112,000 population, $65.1 \%$ brain drain

- Papua New Guinea: 6.3 million population, 36.9\% brain drain

- New Zealand: 4.1 million population, $15.8 \%$ brain drain

These brain drain rates are the share of all tertiary-educated adults from the country who are living in an (another in the case of New Zealand) OECD country and who migrated there after age 18. Both the numerator and denominator are measured with substantial error. The denominator relies on the Barro-Lee estimates of tertiary education in the country, which for Tonga are imputed from attainment in other Pacific Islands. The numerator in many countries is based on the 5 percent or 10 percent subsamples of the census that microdata are available for, which can involve considerable sampling error when it comes to looking at say tertiary-educated Papua New Guineans living in the United States. Moreover, they do not distinguish between tertiary education earned abroad and that earned at home.

\subsection{Selection of a Sampling Frame}

The very name “brain drain” refers to migration of a nation's most highly skilled individuals. As Docquier and Rapoport (2006) note in their New Palgrave Dictionary

\footnotetext{
${ }^{4}$ Brain drain rates are from the new estimates controlling for age of entry, from Beine, Docquier and Rapoport (2007). Additional surveys are also planned for the Solomon Islands and the Federated States of Micronesia.
} 
entry on the brain drain, it is most commonly used in specific reference to the migration of engineers, physicians, scientists, and other very highly skilled professionals. However, common concerns with existing efforts to quantify the brain drain are the extent to which individuals migrate for tertiary training, and the extent to which they self-select into occupations based on the ease of emigration in that occupation. Rather than focus on specific occupations, we therefore choose to focus on individuals with high ability.

We need to specify a well-defined population, in order to construct a sample frame. We therefore define our population of interest as individuals who were at the very top of their country at the end of secondary school. That is, we focus on the "best and brightest" in terms of academic performance. We are not arguing that this is the only population of interest for brain drain - one might also think about talented doctors or business people who weren't necessarily the top of their class in high school - but argue that it is a well-defined part of the population of interest. In particular, it allows us to identify individuals before they have self-selected into particular careers or migrated overseas for tertiary education. ${ }^{5}$ We decided to focus on students graduating high school between 1976 and 2004. Records are likely to be better for more recent students, but they are younger and have had less time to study or work abroad. The choice of 1976 as a starting year was for several reasons. First, Papua New Guinea gained independence in September 1975, so 1976 is the natural starting year in this country as the beginning of the post independence period. Second, our ability to track individuals declines with age, and so we need some limit on how far back we go. Individuals graduating high school in 1976 would be 49-50 years old in 2007-08, the time of our survey, which appeared a useful target maximum age to study. We next discuss how the top students were defined in each country.

New Zealand: Our sample frame in New Zealand is comprised of four groups of individuals, each of which is a well-defined group of individuals who excelled

\footnotetext{
${ }^{5}$ Migration for secondary education is very rare for New Zealanders and Papua New Guineans. It occurs to some extent in Tonga. However, we do not have a well-defined criterion with which to identify who is a top student prior to the end of secondary school, so we concentrate on those who complete schooling in their home country.
} 
academically. ${ }^{6}$ The first are members of New Zealand's Mathematical Olympiad team. New Zealand began sending teams to the Mathematical Olympics in 1988, and sends a team of 6 students per year. These students are selected on the basis of a winnowing process which begins with nationwide mathematics competitions. Since some individuals were in the team multiple years (some in their second-to-last or even third-to-last years of secondary school), over the 1988 to 2004 period there were 73 individuals in the team. The second group consists of members of New Zealand's Chemistry Olympiad team. Four students per year were sent to this competition, beginning in 1992, with students again selected through nationwide competitions. The total number of individuals in the team over the 1992-2004 period was 48.

The third group of individuals we consider are students who were top scholars in the University Bursary examinations over the period 1991-2004. These examinations are taken by almost all students in their final year of secondary school, and are the basis for entrance to University. Beginning in 1991, the New Zealand government publicly named and awarded prizes to the top overall male and female scholars, the top maori and pacific island students, and the top students in each academic subject. Students choose 5 (or sometimes 6) subjects to study in their final year, with top subject prizes awarded in around 28 separate subjects each year. These subjects include more academic subjects such as calculus, physics, biology, chemistry, statistics, English, French, German, as well as art and performance oriented subjects such as music, printmaking, design, photography, and painting. Altogether there were 484 individuals who were either a top scholar overall or a top subject scholar over the 1991-2004 period.

These three groups have the advantage of containing individuals selected through nationwide competitive examinations. In order to obtain a sample frame for individuals graduating over the 1976-91 period, we instead follow the strategy that will be used in Papua New Guinea and Tonga, of selecting the top students from a set of top high schools. We identified a list of 16 secondary schools which had good geographic coverage across New Zealand and which had supplied many of the individuals in the first three groups. We then asked each school for a list of the Dux of the school each year

\footnotetext{
${ }^{6}$ Note the four groups are not mutually exclusive - individuals can enter the sample frame as a result of membership in any one of the four groups, but there are people who are in more than one of the groups listed here.
} 
going back to 1976. The Dux is the equivalent of the Valedictorian in the United States, and is the student who has highest academic performance in the school. This is typically awarded on the basis of performance in school examinations. Altogether there were 271 individuals contained in this group. By way of comparison, 70 percent of chemistry Olympians, 66 percent of maths Olympians, and 51 percent of Bursary top scholars were the Dux or Proxime Accesit (the second best student) at their schools.

Altogether these four groups give a sample frame of 851 highly skilled individuals who graduated secondary school in New Zealand over the 1976-2004 period. Tonga

Primary and Secondary Schooling in Tonga are nearly universal, with a gross secondary school enrolment rate of 99 percent. Education is provided by both Government and Church schools. At the secondary level, there are 10 Government schools and 32 non-Government Church and private schools. Approximately 70 percent of secondary students are in the non-Government schools, with the Government-run schools being viewed as more prestigious, and requiring high grades for entry (World Bank, 2005). Tertiary institutions include an extension center of the University of the South Pacific (USP, which is headquartered in Fiji), the Tonga Institute of Higher Education, the Tonga Institute of Technology, the Queen Salote School of Nursing, theological colleges, Tupou Tertiary Institution, and the Tonga Teachers College. Aside from the USP extension, teaching and nursing schools, the remaining tertiary institutions provide diploma level studies and certificate level courses in technical areas such as accounting and business, computing, general engineering, and hospitality.

Neither Tonga nor Papua New Guinea have participated in the mathematical or chemistry Olympiads, so this definition of a top student can not be used in either country. Many Tongans sit the New Zealand University Bursary examinations, but records are not kept of the top Tongan performances on these examinations. We therefore follow a strategy of selecting top students from selected schools.

We selected as our sample frame the Dux and Proxime Accessit from the top three high schools on the main island of Tongatapu (Tonga High School, Tonga College, and Queen Salote). ${ }^{7}$ In addition, we selected the two top schools in the "outer

\footnotetext{
${ }^{7}$ Tongatapu contains two-thirds of the population and one of the two international airports.
} 
islands”,Vava'u High School and Taufa'ahau I Pilolevu College (TPC) in Ha'apai. ${ }^{8}$ Queen Salote and TPC are mission schools belonging to the Free Wesleyan Church, while the other three schools are Government-run. For each we take top scholars over the period 1976-2004, except for Vava'u High School, which only opened in 1985. This gives a target sample of 266 individuals, ranging in age from 18 to 50.

Websites of the schools provided some initial information on the names of these top students. Each of the schools were then visited, and school teachers and librarians helped to reconstruct the list, using school records and old school magazines. Finally, once some students were contacted, they were used to help verify the names of the other top students in their school at around the same time as them. Using this combination of approaches, we were able to identify the names of 245 of the 266 Duxes and Proxime Accesits.

\section{Papua New Guinea}

In strong contrast to Tonga and New Zealand, PNG is very far from universal education. Net primary school enrolments are less than $60 \%$, and net secondary school enrolments less than $20 \%$. Historically there was a major winnowing of students first at grade 6, and then at grade 10. Grades 11 and 12 were only taught at four National High Schools, where students were given the same funding as tertiary students. As an example of this winnowing process, only 7 percent of the grade 6 cohort in 1995 went on to complete grade 12 in 2001. Education reforms in the mid-1990s introduced a fifth National High School and also allowed many provincial and religious schools to teach Grades 11 and 12. PNG has a reasonably comprehensive tertiary sector with six universities. The University of Papua New Guinea was established in 1965 and offers degree programs, including a medical school and a law school. The PNG Institute of Technology (or Unitech) was established at the same time and offers degree programs in technological and applied sciences. There is also the University of Goroka which was formerly a teacher's college, a University of Natural Resources and the Environment also established in 1965, the Pacific Adventist University established in 1984, and the Divine Word University established in 1980.

\footnotetext{
${ }^{8}$ The Vava'u and Ha'apai island groups contain most of the remaining one-third of the Tongan population and Vava'u also has the second international airport.
} 
School records in PNG were almost non-existent, with no school magazines or boards with the names of the Duxes and Proxime Accesits to provide a record of who the top students were. Records were also not kept in any systematically accessible way by the Ministry of Education. The only formal sampling frame came from the Office of Higher Education (OHE), which allocates slots and scholarships for tertiary study. The OHE provided the names of the 264 students who had achieved a 4.0 GPA in their Grade 12 national examinations during 1995-98 and 2000-2004. On average only 0.7\% of Grade 12 exam entrants in these years achieved this perfect GPA. These 264 students had come from 30 different secondary schools, with 32\% of them from the National High Schools. We therefore created a sampling frame of these 4.0 GPA students and also any Duxes or Proxime Accesits who were not on the OHE list but who were from the top two-thirds of schools supplying the 4.0 GPA group. This gave a potential sampling frame of 624 if the two groups were mutually exclusive and 376 if all of the 4.0 GPA students were also a Dux or Proxime Accesit. ${ }^{9}$

For 1976-1994 our sample frame consists of the Duxes and Proxime Accesits from the National High Schools. This gives a potential sample frame of 152 individuals over this period. However, due to a lack of school records, we were only able to identify the names of 93 of these individuals by asking former students and teachers at these schools, and through radio and television advertisements.

\subsection{Tracking and Surveying}

The second phase consisted of attempting to track down the list of names, and administering the survey to them. We designed a comprehensive survey intended to collect information on many topics needed to measure both the determinants and consequences of highly skilled emigration. The survey contained separate modules for current migrants, return migrants, and never migrated individuals, and averaged just over one hour to complete. All of the New Zealand top students answered the survey online. A mixture of online surveys, in person surveys in New Zealand, Tonga, PNG, and phone

\footnotetext{
${ }^{9}$ This is comprised of a potential 360 Duxes and Proxime Accesits from the top 20 schools plus 16 of the 4.0 GPA students who were from the lower third of schools supplying at least one 4.0 GPA student.
} 
surveys in Australia, Fiji, and the United States were used to survey the top students from Tonga and PNG.

The most difficult part of the fieldwork was tracking down the current location of these top students. A wide variety of methods were used to do so. For the New Zealand top students, the initial points of contact included contact information provided by the organizers of the Mathematical and Chemistry Olympiad teams, the mailing address at the time of graduating high school for top bursary scholars provided under a research agreement with the New Zealand Ministry of Education, and information from the secondary schools used for the sample of Duxes. This was followed up by an intensive internet search, using Google, social networking sites such as Facebook and LinkedIn, alumni networking websites, and other web searches. Finally, this was complemented by social networking among the top scholars, and by telephone book searches in the New Zealand telephone directory.

In PNG and Tonga the first point of contact was their school and local community, with family members and former classmates often providing information on which country migrants were in, and some contact information. The interviews in Tonga were carried out by a former school teacher, with good contacts in schools and churches in Tonga, while those in PNG were carried out by a local survey firm. Migrants were tracked through community networks abroad and through searches of telephone directories in New Zealand, Australia and the United States. Newspaper and radio advertisements in both source and destination countries were also used to try and reach target subjects. Finally internet searches in Google and in ex-students reunion websites helped to track down a few more.

A number of methods were used in order to try and maximize response rates. First, for each of the three countries we used natives of these countries to contact participants. The survey was marketed to participants as a survey of their country's "top students”, and the potential policy uses of the survey explained. Secondly, the use of web-based surveying allowed busy respondents to fill out the survey at a time of their convenience, while in-person surveys of Tongans and Papua New Guineans allowed those without easy access to the internet to participate. Participants received token compensation in the form of either a small monetary payment, a draw for Amazon.com 
vouchers, and in PNG a draw by the Minister of Education with US\$1000 in prize money. Finally, we will disseminate a short summary of the results, and used the fact that these top students would be curious about the lives and experiences of other top students as another incentive for participation.

\subsection{Tracking and Response Rates}

Table 1 summarizes the tracking rates and survey response rates, we discuss in the next section possible biases due to non-response. Tracking and response rates were remarkably high for the Tongan top students - we were able to establish either directly or through verified proxy reporting the current country of residence for all 245 top students whose names had been identified, or 92 percent of the complete sample frame. Of these 245 individuals, 193 individuals answered the survey, a survey response rate of 73 percent of the sample frame and 79 percent of those whose names were known. There was only one or two refusals, the rest were individuals whose country of residence was reported by multiple other sources, but who we were not able to establish contact with.

Tracking and response rates were even higher for the mathematics and chemistry Olympiad team members from New Zealand, with survey response rates of 89-90 percent for both these groups. This reflects the close cooperation of the team organizers, the fact that team members have some connections between each other, the relatively young age of the individuals, and that many of the members ended up in occupations such as computer science or academia where they had established an internet presence. The tracking and response rates were 54 percent and 47 percent respectively for the top scholars in Bursary, and only 35 percent and 25 percent respectively for the pre-1992 Duxes. This reflects both the older age of these individuals, the lack of any existing contact information about them, and that in some cases only their surname and initials were kept in school records. Combining all the groups together, the total tracking and response rates were 55 percent and 44 percent respectively.

Papua New Guinea was the most challenging, due to the non-existent school records, larger population size, poor infrastructure in PNG, and the fact that a vibrant mining sector offers jobs in multiple remote locations within PNG. For the group of 1995-1998 and 2000-2004 top students, where the sampling frame was comprised of 
those who either had a 4.0 GPA or were a Dux or Proxime Accesit from the top 20 schools providing the group of 4.0 GPA students, the tracking and response rates were 39 percent and 29 percent respectively. ${ }^{10}$ For the period prior to 1995, where the sampling frame was the Duxes or Proxime Accesits at the four National High Schools, the response rate was 84 percent of those whose names were known and 51 percent of the complete sample frame for those years. ${ }^{11}$ Combining all the groups together, and also including nine respondents from 1999 who were located directly from schools who had been top suppliers of $4.0 \mathrm{GPA}$ students in previous years, the total tracking and response rates were 43 percent and 34 percent respectively.

\subsection{Are these top students a group that countries would care about for brain drain?}

Our sampling approach targets individuals who were the top in terms of academic performance at the end of secondary school. A natural question is whether these individuals end up in a broad range of occupations that traditional concerns about brain drain would include, or whether these top students end up in a narrow range of restricted academic occupations. The latter would still be of some interest, but would mean that our study is really restricted to the brain drain of academics.

The New Zealand top scholars are the most likely to end up as academics, but even in this case, only one-third of working current migrants and less than 10 percent of working return and non-migrants are in academia. In the New Zealand sample, the main occupations of current migrants are academic or researcher (35\%), management consultant, investment banker, or businessperson (21\%), software developer or other information technology professional (12\%), medical doctor (6\%) and lawyer (5\%). There are also a range of other professions, including an architect, magazine editor, musician, designer, and a professional triathlete. Employers include prestigious universities such as Harvard, Stanford, MIT, Cambridge and Oxford, top global consulting firms such as McKinsey, Morgan Stanley, JP Morgan, top law and accounting firms such as Booz

\footnotetext{
${ }^{10}$ In the achieved sample for these years, 44 percent of the 4.0 GPA students were also a Dux or Proxime Accesit from the top 20 schools so we estimate that the combined sample had 509 students, of whom 196 were located and 149 were surveyed.

${ }^{11}$ For Sogeri National High School, which is the oldest and historically most prestigious school in PNG (e.g. 2 of the 6 PNG Prime Ministers were educated at Sogeri), 76 percent of the sample frame responded, while in the other National High Schools the response rate was only 36 percent.
} 
Allen Hamilton and PriceWaterhouse Coopers, and leading IT companies such as Microsoft and Intel.

The occupations amongst those in New Zealand (non-migrants and return migrants) are more diverse, and include medical doctors (17\%), IT professionals (12\%), academics (9\%), bankers, management consultants and other related business people (8\%), lawyers (7\%) and engineers (5\%). The wide range of other occupations includes artists, a director of television commercials, designers, a pastor, several bureaucrats, and secondary school teachers.

Among the working current migrants from Tonga, the main occupations are medical doctors and nurses (19\%), school teachers (10\%), and bankers and accountants (10\%). Other occupations include an Ambassador, several working in IT, engineers, academics, and a couple of individuals in the U.S. Armed Forces. The main occupations among those working in Tonga are school teachers (28\%), medical doctors and nurses (20\%), public servants such as Secretary and Assistant Secretaries, Deputy Directors, and other such positions in Government departments (13\%), high-level business positions such as company director or chief financial officer (6\%), and accountants and bankers (6\%). Other occupations include a preacher, engineers, lawyers, IT, an aviation consultant, and an academic.

Among the top students from PNG that are working in PNG, the main occupations are in information technology (21\%), engineers (11\%), accounting and finance (7\%), lawyers (7\%), and academics (5\%). A wide range of other occupations includes pilots, geophysicists, a veterinarian, project managers, a malaria statistician, and medical officers. The handful of top students from PNG that are working overseas are in similar occupations: IT, accounting, law, academia, engineering, and nursing.

Thus it appears that the top students are not just academics, and that they engage in a wide range of occupations which incorporate many of the skilled occupations that one might think have positive externalities for development. Thus the migration and return migration of these individuals should be of importance for considerations of brain drain and brain gain. 


\section{The Incidence of Emigration and Return Migration.}

We define migration as ever having worked or studied abroad after finishing secondary school. We do not place a restriction on the minimum amount of time this must have occurred for, but it is very rare for the time abroad to be less than one year for these populations. Table 2 provides the incidence of ever migrating, currently being an emigrant, and being a return migrant among our different populations and samples. In a handful of cases individuals answering the survey answered that they were currently living in the source country, but did not answer the question on whether they had ever studied or worked abroad. We therefore give bounds for the incidences of current migration and return migration in the sample in these cases.

The incidence of ever migrating is very high. In the sample, 83 percent of Tongan top students, 67 percent of New Zealand top students, and 37 percent of PNG top students had ever worked or studied abroad. The incidence of current migration is also high for the Tongan and New Zealand samples, but much lower in PNG. 51 percent of Tongans, 41 percent of New Zealanders, and 9 percent of Papua New Guineans are current migrants. Between one-quarter and one-third of the sample in each country are return migrants: 33 percent in Tonga, 27 percent in PNG, and 26 percent in New Zealand.

Where are these migrants going to? The main three destinations for current New Zealand migrants are the United Kingdom (30\%), the United States (28\%) and Australia (20\%). The remainder are dispersed across a range of other European countries, Canada, Hong Kong and China, other Asian countries, and the United Arab Emirates. The main four destinations for Tongan top students are New Zealand (31\%), the United States (23\%), Fiji (18\%) and Australia (17\%). Other destinations include China, Japan, Canada, Germany, Philippines, India, Vanuatu and New Caledonia. There are fewer current migrants from PNG, with 50\% of them in Australia, 18\% in New Zealand, and the rest scattered among Japan, China, the Solomon Islands, and Laos.

\subsection{Accounting for Individuals Not Surveyed.}

Despite what we consider to be high tracking and response rates given the nature of study, an obvious concern is whether these migration incidence rates are biased due to 
non-response. We employ three methods to examine how robust our estimates are to such concerns.

The first method we use is to simply calculate bounds on the range of possible migration incidences in our data. We use the observed numbers in the sample, and the information known about the locations of individuals not surveyed. For example, let $\mathrm{C}_{\mathrm{s}}$ and $\mathrm{C}_{\mathrm{k}}$ be the number of current migrants in the sample and known among nonrespondents respectively, $\mathrm{N}_{\mathrm{s}}$ and $\mathrm{N}_{\mathrm{k}}$ be the number of individuals who are non-migrants in the sample and among non-respondents respectively, and $\mathrm{T}$ denote the total population. Then a bound for the proportion of current migrants in the population is:

$$
\left[\left(\mathrm{C}_{\mathrm{s}}+\mathrm{C}_{\mathrm{k}}\right) / \mathrm{T},\left(\left(\mathrm{C}_{\mathrm{s}}+\mathrm{C}_{\mathrm{k}}+\mathrm{T}-\mathrm{N}_{\mathrm{s}}-\mathrm{N}_{\mathrm{k}}\right) / \mathrm{T}\right]\right.
$$

Bounds for the incidence of ever migrating and for being a return migrant are calculated in a similar fashion.

These bounds are narrowest for current migrants, since in the case of nonresponders, we at most know their current location, but are unable to distinguish return migrants from non-migrants among those living in the home country. We obtain very narrow bounds in the case of Tonga, and among maths and chemistry Olympians in New Zealand. We can then, for example, bound the rate of ever migrating at between 66 percent and 73 percent for the New Zealand Olympian group, and at between 76 percent and 88 percent for the Tongan top students. The sample proportions are within these bounds in all but one case: that of current migrants among Tongan top students, where in the sample we have 50.8 percent as current migrants, compared to population bounds of between 52 percent and 65 percent. Thus it appears that the Tongan sample slightly undersamples current migrants, although the magnitude of undersampling is not large.

Since the bounds are wider for the New Zealand sample, we carry out a second approach with this group. As one would expect, our success rates for tracking individuals decline with age. For example, among the pre-1992 Dux population, we surveyed 32 percent of those aged under 40, compared to 22 percent of those aged over 40 . Success rates are also slightly lower for females than males (23\% for females vs $28 \%$ for males in the case of the pre-1992 Dux sample), perhaps due to name changes after marriage making it more difficult to find females on the basis of their name in secondary school. We therefore assume that, conditional on age and sex, response is at random, and use the 
observed migration status of the sample to impute the migration status of those not sampled. We predict whether an individual has ever migrated using the predicted probabilities from a probit regression of ever migrating on dummies for five-year age groups and a dummy for being female. Similar probits are carried out for being a current migrant and for being a return migrant. We then combine the imputed migration status for non-respondents with the actual status for survey respondents to arrive at the numbers listed as population estimates in Table 2.

We see that correcting for differential response rates by age and sex in this manner yields estimates of migration incidence which are extremely close to the sample estimates. Thus under the assumption that response is at random conditional on age and sex, the sample estimates are close to unbiased.

Finally, we can examine the reasonableness of this assumption in the case of the pre-1992 Duxes, the New Zealand sample with the worst response rates. Data collection for this group was carried out as follows. A research assistant in New Zealand made a first attempt at searching for these individuals in late 2007 and early 2008, resulting in 39 individuals from this group being surveyed. A second research assistant based in the United States then carried out a more intensive effort to try and track more of these individuals down during the summer of 2008, yielding a further 28 individuals in the survey. The rate of ever migrating among the first group was 77 percent, compared to 79 percent in the second wave $(\mathrm{p}=0.88) .{ }^{12}$ The fact that those who more effort was required to track down have similar migration status to those who less effort was required for suggests that it is not unreasonable to assume that migration status among nonrespondents is similar to those in the sample, conditional on age and sex.

\subsection{Migration and Return Migration by Age}

It therefore appears that at least in the case of Tonga and New Zealand, the migration status of individuals in the sample is broadly representative of that in the population of top students. We now use this sample to explore how the pattern of

\footnotetext{
${ }^{12}$ The difference is also small (less than 0.02) and statistically insignificant after controlling for differences in age and sex among the two subsamples.
} 
migration and return migration varies by age, as a first step towards exploring the determinants.

Our survey asked individuals for retrospective life histories of migration movements. In addition, data on the country where tertiary education was obtained and years during which this was obtained was collected. We use this information to calculate for each individual their migration status at each age from age 18 up to their current age. We begin by pooling these data, assuming that there are no substantial cohort or time effects. Figures 1-3 then plot, for each country, the proportion of all individuals in the sample who had ever migrated, who were a current migrant, and who were a return migrant at a given age. We plot confidence bands around the ever migration and return migration lines, calculated as plus and minus 1.96 standard deviations of the mean. These confidence intervals get wider with age, reflecting that we have far fewer observations on individuals who have ever been 40 years old than we do for individuals who have ever been 20 years old.

Figure 1 shows the rate of migration is fairly low over the ages $18-21$ for New Zealanders. This is the period of initial tertiary studies for most students, and the majority of New Zealand top students undertake undergraduate education in New Zealand. The rate of migration then rises rapidly over the age range 21-28, with less than 10 percent having migrated before age 21 , and 61 percent having migrated by age 28 . There is then a very slow rate of new migration beyond age 28. Age 28 is also the peak age for individuals to be current migrants, with 50 percent of the sample overseas at this age. There is a slow, almost linear, pattern of return migration with age, and by age 40, the sample is almost divided equally into three groups of current migrants, return migrants, and never migrated.

The age pattern is quite different for Tongans in Figure 2. Many of the top students migrate immediately after graduating secondary school, and by age 21, 54 percent have ever migrated. This reflects the relative lack of tertiary education opportunities in Tonga, with many migrating to receive undergraduate education abroad. As with the New Zealand sample, there is very little new migration after age 30 . However, the proportion who are current migrants and who are return migrants also 
levels off around age 30, and the proportion who are current migrants dominates those who are return migrants.

We only show the age patterns for PNG up to age 31, reflecting the larger sample graduating secondary school over 1995-2004. The incidence of migration is much lower than in the other two cases. There is very little migration before age 21, consistent with most Papua New Guinean top students carrying out their undergraduate education at one of PNG's universities. There is then gradual emigration from age 22 to 30, with return migration at approximately the same rate. Much of this is from students going to Australia for Masters degrees on scholarships which bond them to return home, and workers such as pilots getting sent abroad by their employer for work experience, with again a bond to return home. Nevertheless, not all migration is of this type, and by age 31 there are 21 percent of the top students currently abroad.

\subsection{Are there significant cohort differences in the age patterns of migration?}

We next examine whether the age pattern of migration varies by cohort. We define five cohorts in terms of their current age: currently aged 18 to 24 , currently aged 25 to 29 , currently aged 30 to 34 , currently aged 35 to 39, and currently aged 40 and above. Figures $4 \mathrm{a}, 4 \mathrm{~b}$ and $4 \mathrm{c}$ then plot the proportion in the cohort who had ever migrated at each given age.

Figures $4 \mathrm{a}$ and $4 \mathrm{~b}$ show that the age patterns for New Zealand and Tongan top students are reasonably similar across different cohorts, although there is some tendency for younger cohorts to have higher migration rates at ages 18 to 21 than the older cohorts in these countries did. We test whether these cohort differences are significant by estimating probit regressions of ever having migrated at age 21, age 25, and age 30 as a function of dummies for these cohort groups. There is a significant difference among cohorts $(\mathrm{p}=0.015)$ at age 21 for New Zealanders, but not for ages 25 and 30. This difference is no longer significant when we also add controls for the reason the individual entered the sample (maths Olympian, chemistry Olympian, pre-1992 Dux). Among Tongans, there is no significant difference in migration rates among cohorts at ages 21 and 25 , but there is at age 30 , where the cohort currently aged 35 to 39 has a higher migration rate than both the earlier and the later cohort. 
Figure 4c shows the age patterns for PNG cohorts are very similar for the three younger cohorts (those aged 18 to 24, 25 to 29 , and 30 to 34). However, they are different for the older two cohorts. We only have data on age of first migration for 9 individuals in the 35 to 39 cohort, whereas we have data on 47 individuals currently aged 40 and above. This older group has higher migration rates in the sample than the younger cohorts. However, due to the relatively low tracking rates in PNG, this may simply reflect differences in who responded to the sample by cohort, rather than differences in migration patterns by cohort.

\section{Modeling the Determinants of Migration.}

Migration in our context includes both migration for work abroad, and migrating to undertake tertiary education abroad. The two are often interrelated - migrants may obtain overseas qualifications as a pathway to working abroad, may work abroad for several years after completing their undergraduate education before returning to undertake graduate study, or may work and study at the same time. Table 3 considers the extent to which current and return migrants have worked and studied abroad. We have almost complete data on study abroad. Individuals are classified as having worked abroad if they are current migrants and are working, if they are return migrants and say they worked while abroad, or if they list work as the reason for migration. However, there is significant item non-response on some of these questions, which appeared towards the end of the survey, and this data is not available for some of the Tongan sample who received an abridged questionnaire over the phone. We therefore show bounds for the percentage working abroad, and who have both worked and studied abroad.

Table 3 shows that approximately half of the migrants from each country have both worked and studied abroad. Working abroad is near universal for the New Zealand sample, with 50 percent having studied abroad. Studying abroad is universal for the Tongan sample of migrants, with between 36 and 76 percent having worked abroad. The PNG sample has relatively high levels of both studying abroad (88 percent), and working abroad (46 to 66 percent). 


\subsection{Modeling the Decision to Migrate}

Standard models of migration (Sjaastad, 1962; Borjas, 1987) view migration as an investment decision, in which potential migrants weigh up the gain in wages from migrating with the costs of doing so. The emphasis in these models is on income maximization as the reason for migration, despite the underlying theory being based on utility maximization. One reason for this is that they are interested in differences in migration propensities across skill levels. In contrast, our focus is on the difference in migration propensities within a quite narrow skill level. In our context then, the other components of utility maximization may matter more. For example, following Grogger and Hanson (2008), consider a linear utility model ${ }^{13}$ where the utility associated with working in location $h$ for person $i$ of skill level $j$ is:

$U_{i, h}^{j}=\alpha\left(w_{i, h}^{j}-C_{i, h}^{j}\right)+\varepsilon_{i, h}^{j}$

Where $w_{i, h}^{j}$ is the wage earned from working in location $h$, and $C_{i, h}^{j}$ is the cost associated with migrating to location $h$, which is zero for the home country. Assuming that the error term $\varepsilon$ follows an extreme value distribution, the log odds of migrating from the home country $h$ to the destination country $d$ are:

$\alpha\left(w_{i, d}^{j}-w_{i, h}^{j}\right)-\alpha C_{i, d}^{j}$

We view the cost term as also implicitly including the psychic as well as financial costs of migrating, and the cost to utility of the risk and uncertainty associated with how much can be earned abroad. We will attempt to measure proxies for some of the determinants of this cost term, as well as considering the income gain.

Typical studies of migration selectivity assign $j$ to different skill groups in terms of education outcomes. However, in our case the education decision is intertwined with the migration decision, and ultimate education levels are themselves a function of migration. Some form of tertiary education is almost universal for these top scholars in all three countries. Table 4 shows the educational attainments of our sample. Classifying

\footnotetext{
${ }^{13}$ There is some debate in the literature as to whether maximization of levels or logs of incomes better describes the data. See e.g. Belot and Hatton (2008), Grogger and Hanson (2008), among others. We will consider both linear and log wages.
} 
medical and law degrees as graduate degrees ${ }^{14}$, we see that two-thirds of the New Zealanders, half of the Tongans, and one-third of the Papua New Guineans have undertaken graduate education.

Table 5 then carries out what would be the typical test of educational selectivity, comparing the migration rates of top students with different levels of education. We see that students with PhDs, and the group of those with any graduate degree have higher migration rates than those without these qualifications in each country. This would suggest positive educational self-selection, and in a framework like (2), would be typically explained by higher returns to education abroad than at home. However, the last column of Table 5 shows that 52 percent of New Zealanders with graduate degrees studied abroad, as did 66 percent of Papua New Guineans and 100 percent of Tongans with graduate degrees. Those with $\mathrm{PhDs}$ are even more likely to have obtained them abroad. As such, the standard analysis of returns to skill and educational selectivity is misleading, since education is itself a result of migration, rather than a determinant.

\subsection{What are the income gains from migrating?}

We therefore begin our analysis of the determinants of migration by attempting to estimate what the gain in income is from migrating, effectively capturing the first term in equation (3). We consider two approaches to measuring the gain in income from migration. The first is to regress the income earned by worker $i$ on indicators for his or her migration status, and a vector of individual characteristics:

$$
\text { INCOME }_{i}=\pi+\beta C U R R E N T M I G R A N T_{i}+\delta R E T U R N M I G R A N T_{i}+\lambda^{\prime} X_{i}+v_{i}
$$

We begin by just conditioning on age and sex. It is not clear whether we should control for education, since education attained through migration is one channel through which migration can increase incomes. Nevertheless, controlling for education may help us better compare current and return migrants. We therefore present estimates both with and without conditioning on education.

\footnotetext{
${ }^{14}$ Medical and law degrees are undergraduate degrees in New Zealand, but last for longer than standard undergraduate degrees. Students in these fields often also undertake further specialization studies. Since these are taught as graduate programs in some countries, we classify anyone with a medical degree or law degree as having graduate education.
} 
The typical concern with a regression of this form is that if individuals who stand to gain more income from migrating self-select into migration, then the estimate of $\beta$ will be biased upwards. This may be less of a concern in our application given that the entire sample consists of very high ability individuals.

As an alternative approach, we can measure the gain in income from migrating by asking the top students directly. We asked current migrants what job they would do if working in their home country and how much they thought they would earn from it, and return migrants what job they thought they would have if working abroad and how much they thought they would earn from it. Both groups were assumed to have reasonable knowledge of employment prospects in the other country, and almost all could provide an answer to this question. We did not ask non-migrants how much they thought they could earn abroad, so restrict this to those who have ever migrated only. The income gain from migration is then the self-assessed difference in incomes. For comparison purposes, we also re-estimate equation (4) just for the current and return migrants. These selfassessments will not suffer from the same bias as the regression. However, they may be biased upwards if people self-validate by asserting they would earn less in the other location than they would in the current location, or be biased downwards if both current migrants and return migrants believe the "grass is greener" in the other location. In practice the magnitudes of the counterfactual incomes people report seem to a first order accurate for both groups, so such self-reporting biases do not appear large.

Both approaches requiring converting incomes earned in different currencies into a common unit of analysis. We consider two methods of doing this. The first is to convert all income figures into March 2008 United States Dollars at the Interbank Exchange Rate. The second is to convert into PPP U.S. Dollars using the Purchasing Power Parity exchange rate from the Penn World Tables. However, there are several reasons to believe that the PPP rates are not the right benchmark here. The first is that neither PNG nor Tonga were benchmark countries for the International Comparison Program (ICP). Their PPP exchange rates are therefore estimated solely on the basis of GNI per capita and the secondary school enrolment rate. Fiji appears to be the only Pacific country covered under the ICP, and it is a large outlier when such a model is used, with more expensive 
prices than predicted. ${ }^{15}$ The reason is that the IPC regression model takes no account of small country size, rugged terrain, and remoteness which increase prices. Indeed, our own comparison of prices in Tonga to those in New Zealand suggests that the correct PPP exchange rate should be approximately the prevailing exchange rate between these two countries, not the imputed rate. The difference is quite large: the PPP rate has 1.272 Pa'anga = \$1US, compared to an official exchange rate of 2.075 Pa'anga $=\$ 1 \mathrm{US}$.

The second reason that we believe PPP may not be the right benchmark is that if migrants plan on returning with earnings saved from abroad, or if they are remitting, then the actual exchange rate is what matters for determining the purchasing power of income earned abroad in the home country. For both these reasons, we believe use of PPP makes incomes in PNG and Tonga appear more attractive than they are in reality.

Table 6 presents these estimates for the gain in weekly income from migration. Estimation is carried out for the sample that are currently working and who are currently not students. For the New Zealand top students, the PPP and actual exchange rate results give similar numbers. The mean gain in income from migration according to the regression is between 800 and 1000 U.S. dollars per week. The mean self-assessed change in levels is $815-899$ per week, and thus of similar magnitude to the regression estimate. The mean income of those working in New Zealand is \$US1250 per week, so this represents a 64 to 80 percent increase in mean income from migrating. The mean change in log income is also similar between the regression and self-assessed methods, between 0.44 and 0.56 . There is thus a large gain in average income to be had in both PPP and exchange rate terms from migration.

For the Tongan sample the PPP estimates of the gains are a little lower than those using the prevailing exchange rate, but as noted, we believe the PPP estimates understate the effective gain. Using the exchange rate, the gain in income according to the regression estimates is between 700 and 1200 U.S. dollars per week, compared to a mean income in Tonga of only US\$246 per week. The self-assessed change is US\$728 per week, which is not significantly different from the regression estimates. In logs, the gain in income is 1.2 to 2.0 log points. Thus by any measure the average gain in income is huge.

${ }^{15}$ International Comparison Program (2008). 
In the PNG sample, using PPP we see no significant change in income from migrating, whereas using the actual exchange rate the gain in income is again in the order of US\$740-1100 per week, comparable to the gain for both New Zealand and Tongan top students. As discussed above, we believe the estimates using the exchange rate are more accurate. Note however that the PNG estimates are based on 149 individuals working in PNG and only 11 current migrants working abroad, so that this small sample size of migrants should make one very cautious in these estimates. Nonetheless, again they suggest that there is a large average gain in income from migrating.

Moreover, the fact that we get similar (and large) estimates of the income gain from migration both with and without controlling for education, and from both the regression and self-assessed methods suggests that selectivity biases are unlikely to be having a first-order effect on the estimates.

Of course in addition to estimating the average gain in income from migrating, it would be of interest to examine the returns to different qualifications at home and abroad. However, small sample sizes limit the extent to which we can do this - not to mention the fact that migration is linked to the attainment of many qualifications. For the New Zealand sample, which has the largest sample size, the difference in incomes is greatest for those without graduate education, and least for those with $\mathrm{PhDs}$, suggesting the incentive to migrate (or at least remain abroad after getting education) for income gains should be largest for those with the least education among these top students. The current migrants with only undergraduate education are typically in management consulting, IT, and hedge funds, which are all very lucrative occupations abroad.

The top of Table 7 presents the results of quantile regressions of equation (4) to examine the heterogeneity in income gains from migrating. The bottom of the table presents quantiles of the self-assessed change in income, which we only have for current and return migrants. The quantile regression estimates show the income gains are still sizeable at the $25^{\text {th }}$ percentile, and are very large for the $75^{\text {th }}$ percentile and above. ${ }^{16}$ Both methods suggest income gains for the top 10 percent in the order of 1500 to 2000 USD per week, or 75,000-100,000 USD per year!

\footnotetext{
${ }^{16}$ The small number of current migrants working in the PNG sample makes the quantile regression estimates jump around a lot for PNG.
} 
A second important point to note from Table 7 is that most individuals stand to gain income from migrating, but there is substantial heterogeneity in the amount to be gained. This is important, since it provides variation in income gains that we can use in analyzing the determinants of migration and return in the next section. For New Zealand top students, 82 percent of current migrants and 87 percent of return migrants believe their income would be higher abroad $(\mathrm{p}=0.47)$; for Tongan top students, 74 percent of current migrants and 90 percent of return migrants believe their income would be higher abroad ( $\mathrm{p}=0.23$ ); and for PNG top students, 79 percent of return migrants and 82 percent of current migrants believe their income would be higher abroad $(\mathrm{p}=0.81)$.. Thus it appears that there is not only a large average gain in income from migrating, but that gains occur for the vast majority of migrants.

\subsection{What explains who migrates and who doesn't?}

In light of these large gains in income to be had by migration, what explains who migrates and who chooses not to take advantage of these large gains? In particular, we would like to identify characteristics which were plausibly predetermined at the time of finishing secondary school and which are predictive of whether an individual will later emigrate. We control for age and sex, since older individuals have had more time over which to emigrate, and we are interested to see whether the rate of emigration varies by sex. Taking the utility maximization framework in equation (2), we then seek variables which are associated with either the income gains of emigrating, or the costs of emigrating.

The first set of such variables we consider are the choice of subjects studied in secondary school. These are predetermined at the end of secondary school, but not necessarily exogenous since students who want to move overseas may choose the secondary school subjects which maximize their chance of going abroad. Nevertheless, selection of secondary school subjects is at least at an earlier stage than choosing a major at the tertiary level where we might expect the likelihood of migration to induce a greater influence. We asked students which subjects they studied in their ultimate year of school, and create two dummy variables. The first is for having studied a foreign language other than English. Studying French, German, Chinese, Japanese or other languages will 
reduce the costs of working in another country, and also add a non-monetary utility gain from migrating - the opportunity to practice and extend these language skills should be a strong incentive for migration. The second dummy variable is for having taken all three of the science subjects: biology, chemistry and physics. Top students with a predilection for sciences may be more inclined to study overseas where scientific laboratories are better equipped, or to pursue careers in engineering or computer science which are internationally mobile. ${ }^{17}$

The second set of variables we consider are family wealth. We expect family wealth to affect the migration decision in several ways. Wealthier families can better afford the costs of paying for emigration, arranging work permits, and/or paying for education abroad. This should lead to a positive association between wealth and migration. However, family wealth may also increase the income opportunities available domestically, either directly through employment in a family enterprise, or through family social networks helping to arrange better paying jobs. We would expect both channels to be stronger for Tonga and PNG than for New Zealanders. We proxy for family wealth in two ways. The first is to ask students if their family had above average wealth, average wealth, or below average wealth while they were in secondary school. The second is to ask students how many overseas trips they made while in secondary school. The latter measure is less subject to concerns about reporting of wealth levels, but may also influence the likelihood of migration through exposure to overseas lifestyles, rather than just reflecting a wealth effect.

We also consider parental education as a driver of migration. Parental education is traditionally strongly associated with educational outcomes, and for this reason may be linked to migration for education. However, it is less clear that, conditional on being a top student in secondary school, parental education should have as strong an influence on tertiary education choices as it would in a random sample of the population. Parental education is also likely to be correlated with wealth, and influence the costs and benefits of migration through this channel.

\footnotetext{
${ }^{17}$ A large number of students take mathematics in their senior year of secondary school, so this appears to distinguish science and computer-science oriented students less from other students than does taking three science subjects.
} 
The costs of migration are also likely to be lower for individuals who were immigrants to the country they attended secondary school in. These individuals may have an easier time gaining admission to an overseas country, and will likely experience lower assimilation costs. This is particularly relevant for the New Zealand sample, where 31 percent of top students were born outside New Zealand. It is less relevant for Tonga, where 7.8 percent of top students were born outside Tonga, and PNG, where only 2 percent were born outside PNG.

Adding uncertainty and multiple periods to the utility maximization problem will make the decision to emigrate also depend on risk preferences and the rate of time preference. We measure risk preferences by means of a question taken from the German Socio-Economic Panel, which asks individuals to state on a 11-point scale whether they are generally a person who is fully prepared to take risks or someone who tries to avoid taking risks. This has been used in the study of migration by Jaeger et al. (2007), and like them we are forced to assume that attitudes towards risks are intrinsic characteristics of individuals which are not affected by their migration decision. Although potentially problematic, one piece of evidence that might support this assumption is that we can not reject that the mean risk score is the same for each age group over the 21 to 30 age range, a range in which the rate of ever migrating is increasing strongly.

We measure patience by a dummy variable which takes the value one if an individual would accept $\$ 1100$ in one year's time compared to $\$ 1000$ today. Since migration for both work and education can be construed as an investment with short-term costs required to be paid to achieve longer term gains, we might expect more patient individuals to be more likely to migrate. Again this is measured ex post, but we do not see the proportion who are patient changing with age over the 20s, when migration rates are increasing dramatically.

Finally, we consider macroeconomic variables which might explain why an individual graduating at one point in time might migrate, whereas another migrating at a later date might not. We consider two such variables. The first is the real effective exchange rate ${ }^{18}$ over the age range where the incidence of new migration is highest. We take age range 22 to 25 for Tonga and New Zealand, and age range 25 to 28 for PNG. A

\footnotetext{
${ }^{18}$ Source World Bank Central Database.
} 
high real effective exchange rate means that foreign earnings have less purchasing power in the home country, which we would expect to lead to less migration. For example, migration for work should be more attractive to New Zealanders who were at the key age for deciding on an initial migration in 2001 when the real exchange rate index was 98 (and when \$1US = \$2.46NZ) than in 2007 when it was 137 (and \$1US = \$1.30NZ). The second macro variable we include is the difference in GDP growth per capita in the home country relative to the average GDP per capita growth in the main destination countries during this same age range. We should expect a negative relationship of this variable with migration - the better is growth at home relative to abroad the less likely migration should be.

\subsection{Results on the Determinants of Ever Migrating}

Table 8 presents the results of estimating a probit model for the determinants of ever migrating as a function of these variables. We first estimate the determinants separately by country, and then pool the three countries together since the signs generally go in the same directions and the sample sizes are relatively small in the single country analysis. ${ }^{19}$ First of all, unsurprisingly, the likelihood of ever having migrated increases with age. However, there is no difference in migration rates of male and female top students. Also somewhat surprisingly, there is no difference in the migration rates of top students who were born abroad from those who are born in the home country. Since this group is largely immigrants to New Zealand, this might reflect that parents have moved to New Zealand so that their children can undertake education there, with this effect offsetting the lower costs of migration for immigrants.

The strongest predictors of ever migrating are from variables that might be broadly interpreted as measuring preferences. We find a strong positive association between studying foreign languages or three sciences in secondary school and subsequent migration. Between 24 percent and 39 percent of top students in each country took three science subjects, and this is associated with a 21 percentage point higher likelihood of migrating. Foreign languages other than English are rare in PNG and Tonga, with less

\footnotetext{
${ }^{19}$ Note that in particular the sample size becomes small for Tongan top students, due to significant item non-response on the online survey and to some variables not being included in the abridged phone surveys.
} 
than 2 percent studying them - all of whom migrated. However, 33 percent of New Zealand top students took a foreign language, and this is associated with a 19 percentage point higher likelihood of migrating.

Risk preferences and patience are also associated with migration in the way theory would predict. Risk seeking individuals are more likely to have ever migrated, with a one standard deviation difference in risk seeking score associated with a 6 to 8 percentage point higher likelihood of having ever migrated. More patient individuals are 12 to 13 percentage points more likely to have ever migrated.

In contrast to the strong role for preferences, we find only a weak role for wealth and an even weaker role for macroeconomic factors. The 26 percent of the pooled sample who had taken two or more trips abroad during secondary school have a higher incidence of migration, but not significantly so. The 28 percent who classify their families as having above average wealth at the time of secondary school are marginally more likely to have migrated, but this is not significant when we control for country fixed effects. Children whose mother's did not have tertiary education have slightly lower, but not significantly so, levels of migration.

The macroeconomic variables have a small and statistically insignificant relationship with the likelihood of migration in the pooled sample. The only country for which there is an association is Papua New Guinea, where the real exchange rate is negatively associated with migration. However, in PNG the real exchange rate experienced a secular decline over the sample period, giving it a 0.92 correlation with age. Therefore it is hard to separate the effect of the exchange rate from a non-linear age effect in this case. If we add to this the uncertainty surrounding the small size of the PNG sample for older age groups, there seems reason to question this macro effect even in the case where it is significant.

Finally, in columns 8 and 9 we show that the results are similar if we consider the determinants of ever working abroad. We present this for robustness only, since in many cases migration for study naturally leads onto work, migrants may upskill abroad before working, and we only observe whether or not individuals worked while abroad, not 
whether or not they migrated with the intention to work. ${ }^{20}$ The main point here is that the results are not being driven by migration purely for study.

\section{Modeling Return Migration}

In light of the large income gains to be had from migration, the natural follow-up to Portes’ question of why everyone doesn’t migrate is to ask why so many return. Yang (2006) notes that return migration is a puzzle to exclusively income-maximizing models of migration, and he summarizes two competing theories which may explain return. The first motive for return, which he terms "life-cycle" assumes that migrants prefer consumption in their home country to consumption overseas, and thus chose to return when the marginal lifetime benefit from the additional income being earned overseas falls below the marginal utility cost of being away from their home country. The second motive for return is if there are liquidity constraints and minimum investment levels in the home country, with migrants returning once they reach a certain target-earnings level. Borjas and Bratsberg (1996) discuss a third motive for return, which is that immigrants return if they experience worse-than-expected outcomes abroad. We summarize these three motives as preferences, wealth, and wages respectively.

\subsection{Push-pull factors for migration and return}

To better unpack the role of preferences, wage opportunities, and other factors which influence the change in utility from migrating, we asked individuals about a set of 31 factors which might determine their choice of whether to stay in their home country or live overseas. These factors were adapted and expanded from a list of lifestyle, family, career, cultural, and economic factors developed by industrial psychologists on a nonrandom sample of expatriate New Zealanders (Jackson et al, 2005). Each factor was answered using a Five-point Likert scale, ranging from “draws me strongly towards my home country" to "draws me strongly towards overseas". We clearly do not wish to assume that all of these factors are exogenous to the migration decision, but view them as

\footnotetext{
${ }^{20}$ Moreover, we lose a handful of observations for which we know that they have migrated abroad at some stage, but not whether or not they worked while abroad.
} 
a useful descriptive tool for better understanding some of the factors behind the migration decision that otherwise can not be captured in the data.

Figures 5, 6 and 7 graph the mean responses for each factor for current migrants (denoted migrants), return migrants, and non-migrants from New Zealand, PNG and Tonga. There is broad agreement across migrant groups and across countries in terms of many of the push and pull factors. In all three countries, salaries, job availability in their field, career opportunities in the next two years (short-term career), and possibilities for long-term career advancement are factors which draw individuals towards overseas. Climate and location of own relatives draw individuals in all three countries towards their home country.

New Zealand also draws its top students back as a place to bring up children, for lifestyle reasons, and for public services such as safety and security, children's education, and the quality of the health care system. In contrast, for both Tonga and PNG, health care and education are stronger draws overseas than salaries or career concerns. Finally, it is noticeable that in all three countries several of the issues which often headline media discussion of policies to stem emigration are viewed by top students as neither strongly drawing them abroad or to stay at home. These include tax rates on high incomes, regulations which determine how easy it is to become an entrepreneur, and student debt. Likewise, cultural explanations for emigration, such as the extent to which jobs depend on who you know, and cultural attitudes towards success ${ }^{21}$ are viewed as second-order compared to many of the other factors discussed here.

Note however that if current migrants, return migrants and non-migrants all equally view a factor as drawing them overseas or drawing them towards their home country, such a factor will not help explain why some migrate or why some migrants return, and why others do not. Instead we need to consider factors which are differentially viewed as push-pull factors by the different migrant groups. We test for these differences conditional on other individual characteristics in the next subsection.

\footnotetext{
${ }^{21}$ A classic example of this is what is known as the "tall poppy syndrome" in New Zealand, Australia and Canada, in which a social leveling attitude seeks to cut down those who excel.
} 


\subsection{What determines return migration?}

The return migrants in our sample had been abroad for an average of 5.5 years for the Tongans, and for 3 years for the New Zealanders and Papua New Guineans.

Table 9 presents the marginal effects from probit estimation of the correlates of being a return migrant among the sample of individuals who have migrated. We pool current and return migrants across the three countries, with country fixed effects included, since the sample sizes are small for each country, and the results from countryby-country estimation are qualitatively similar across countries. Approximately 40 percent of the combined sample are return migrants. The one variable that differs most across countries is the role of short-term career considerations, which are a stronger predictor of return migration for New Zealanders than the other countries. We therefore interact this variable with a dummy variable for New Zealand top students.

Again substantial item non-response on the online surveys and the abridged nature of the telephone surveys means that not all variables are available for every returned and current migrant. For this reason we first investigate the role of various sets of variables, before combining together. We always include age and gender, with older migrants more likely to have returned than younger migrants, as was clear in Figures 1, 2 and 3. As with the initial decision to migrate, there is no significant gender difference in whether migrants return. In contrast to the small and insignificant role of being born outside the home country on the initial decision to emigrate, those who do migrate and were born overseas are much less likely to return. This is consistent with these individuals having weaker ties to the home country, and an easier time assimilating and obtaining residence abroad.

Columns 1 and 2 then examine the role of wealth in the return migration decision. Recall that the liquidity constraints theory would predict that poorer individuals should be more likely to return, since they would be more likely to have migrated to alleviate liquidity constraints at home. In contrast, we find wealth to be positively correlated with return migration. This is consistent with the channel discussed in Section 4.3, whereby family wealth may also increase the income opportunities available domestically, either directly through employment in a family enterprise, or through family social networks helping to arrange better paying jobs. 
Columns 3 and 4 then investigate the role of some of the preference variables that were found to be strongly correlated with the initial decision to emigrate. In contrast to this strong association with ever migrating, we find that risk seeking, patience, and the subject choice in secondary school are not significantly associated with whether or not a migrant returns.

Column 5 then examines whether the likelihood of returning varies according to educational achievement. We find that individuals with PhDs are significantly less likely to have returned. In the combined sample, only 18 percent of ever migrants with a PhD have returned, compared to 50 percent of ever migrants without a $\mathrm{PhD}$. Controlling for age, gender, and country of origin, this gap remains a 32 percentage point difference in the likelihood of having returned. In contrast, there is no significant effect of having a medical degree, law degree, or other masters degree on the likelihood of return.

Column 6 directly tests the role of income gains from migration in explaining who returns. If it were only those migrants who discover that income abroad is less than they expected who return, as Borjas and Bratsberg (1996) speculate, then we would expect a strong negative effect of this change in income from migrating abroad on the likelihood of return. Instead we find a point estimate which is close to zero and insignificant.

Column 7 next looks at the role of family in the decision to return. Top students who have ever migrated are more likely to have returned to their home countries if they have a parent alive in the home country, and less likely if they have a spouse who is a citizen of another country. The majority (87\%) of the pooled sample have a parent alive in their home country, while $14 \%$ are married to a foreign citizen. This strong role for family is consistent with the "life-cycle" theory of return, with family shaping the preference for consumption in the home country or abroad country.

Column 8 examines three of the push-pull factors described in Figures 5, 6 and 7. We consider the extent to which salaries, lifestyle, and careers draw individuals abroad, since these were all factors found to be strong push or pull factors, and the role of families is measured directly by the parent and spouse variables. We see a small and insignificant role for salaries, which is consistent with column 6 in showing that income gains are not the prime determinant of return. In contrast, the extent to which lifestyle 
draws individuals abroad is a negatively associated with return migration, significant at the $1 \%$ level. The draw of career possibilities is not a significant determinant for Tongan or PNG top students, but is for New Zealand top students.

Column 9 combines all of these variables together for the sample which answered all these questions. The point estimates are broadly similar to those in the earlier columns. Return migration is found to be more likely for individuals with a parent alive in their home country, who are attracted by the lifestyle in their home country, and who don't have a PhD. For New Zealand top students, return is less likely for those who find their career prospects to be stronger draws abroad.

These econometric results also broadly match the responses given by return migrants when they were asked why they returned in an open-ended question. The most common responses had to do with lifestyle, family, and a strong sense of personal connection to their home country. Among New Zealand top students, only a couple mentioned a job opportunity in the home country as the reason for return, and none directly mentioned better pay in the home country. Some of the return of the PNG and Tongan top students was non-voluntary - 31 percent of Papua New Guinean returnees and 14 percent of Tongan returnees said they returned because either the scholarship or work agreement they were on required them to return to their home country. The most common cause of this was AusAid scholarships requiring them to return to their home country for two years after receiving tertiary education in Australia. However, there appears to have been little subsequent emigration of individuals who returned because of such restrictions. Another common answer among Papua New Guineans and also expressed by some Tongans was a desire to contribute to the development and progress of their home country.

\section{Conclusions and Policy Implications}

We have successfully tracked down a high proportion of the very top performers in secondary school over the period 1976 to 2004 from three Pacific countries. The results reveal very high rates of emigration among top students during their twenties, together with significant levels of return migration. For both the initial decision to emigrate and the decision to return, we find that narrow measures of the income gains or 
economic incentives for migrating play a very minor role in determining which of the highly skilled migrate and return and which do not, whereas preference variables are strong predictors. This leads us to conclude that an income maximization framework is not the appropriate model for analyzing the first-order determinants of migration of the best and brightest, and that more emphasis needs to be put on the non-income components of the utility maximization decision.

These results also have implications for the types of policies which are most likely to succeed in allowing countries to better attract back their highly talented individuals. Whilst much of the policy debate has centered on the need for higher salaries and lower taxes ${ }^{22}$, our work shows return migrants are giving up approximately US\$1000 per week to return to their home countries. Our results suggest that marginal changes in tax rates or salary levels are unlikely to change the migration decision, whereas policies which change the non-income benefits of being in the home country may have more effect.

Indeed, when asked an open-ended question about which policies they would personally recommend to Government officials and Universities trying to attract back top students, the current migrants in our survey offer suggestions more closely linked to improving the career opportunities rather than to simply raising salaries. The New Zealand top students comment on the relatively poor environment for academic research in New Zealand compared to abroad, requesting better funding for scientific laboratories, increased research grant opportunities, and more specific requests such as the removal of regulations that make it difficult to work in genetic engineering and related biological fields. The majority of Tongan emigrants answering this question answered with respect to issues of political and institutional reforms. These included calls for more transparency in government, more democracy, allowing dual citizenship, land reform, and improving the civil service so that pay is more closely linked to performance and merit rather than to tenure. As noted, our sample contains few current emigrants from PNG. Their two main areas of recommendations are removing a dual salary system which pays foreigners differently from locals in certain occupations, and allowing dual citizenship. And in all

\footnotetext{
${ }^{22}$ See e.g. "Higher Salaries best way to reverse brain drain”, New Zealand National Party Press Release December 9, 2004. http://www.scoop.co.nz/stories/PA0412/S00222.htm [accessed December 2, 2008].
} 
three countries, current migrants gave improving the overall economy as a more important priority than lowering income taxes, or increasing salaries.

\section{References}

Beine, Michel, Frederic Docquier and Hillel Rapoport (2007) "Measuring international skilled migration: a new database controlling for age of entry" World Bank Economic Review, 21(2): 249-54

Beine, Michel, Frederic Docquier and Maurice Schiff (2008) "Brain Drain and its Determinants: A Major issue for small states”, IZA Working Paper No. 3398

Belot, Michele and Timothy Hatton (2008) "Immigrant Selection in the OECD”, CEPR Working Paper No. 6675

Borjas, George J. (1987) “Self-Selection and the Earnings of Immigrants.” American Economic Review 77(4): 531-553.

Borjas, George and Bernt Bratsberg (1996) "Who Leaves? The Outmigration of the ForeignBorn", Review of Economics and Statistics 78(1): 165-76.

Commander, Simon, Mari Kangasniemi and L. Alan Winters (2004) "The Brain Drain: Curse or Boon? A Survey of the Literature”, in R. Baldwin and L.A. Winters (eds.) Challenges to Globalisation: Analyzing the Economics . NBER and University of Chicago Press.

Docquier, F, O. Lohest, A. Marfouk (2007) "Brain drain in developing countries”, World Bank Economic Review, 21(2): 193-218.

Docquier, Frédéric and Abdeslam Marfouk (2005) "International Migration by Education Attainment, 1990-2000”, pp 151-99 in C. Özden and M. Schiff (eds.) International Migration, Remittances and the Brain Drain. New York: Palgrave Macmillan.

Docquier, Frédéric and Hillel Rapoport (2006) “The Brain Drain”, in L. Blume and S. Durlauf (eds.) New Palgrave Dictionary of Economics (second edition), London: Palgrave and MacMillan.

Grogger, Jeffrey and Gordon Hanson (2008) "Income Maximization and the Selection and Sorting of International Migrants”, Mimeo. UCSD.

International Comparison Program (2008) Global Purchasing Power Parities and Real Expenditure: 2005 International Comparison Program. The World Bank: Washington, D.C.

Kapur, Devesh and John McHale (2005) "Give us your best and brightest: The global hunt for talent and its impact on the developing world”, Center for Global Development: Washington, DC.

Jackson, Duncan, Stuart Carr, Margot Edwards, Kaye Thorn, Nicola Allfree, Jill Hooks and Kerr Inkson (2005) "Exploring the Dynamics of New Zealand's Talent Flow”, New Zealand Journal of Psychology 34(2): 110-116.

Jaeger, David, Holger Bonin, Thomas Dohmen, Armin Falk, David Huffman, and Uwe Sunde (2007) “Direct Evidence on Risk Attitudes and Migration”, IZA Working Paper No. 2655.

McKenzie, David and Hillel Rapoport (2008) "Self-selection patterns in Mexico-U.S. migration: the role of migrant networks", Review of Economics and Statistics, forthcoming.

OECD (2005) Trends in International Migration: SOPEMI 2004. OECD, Paris.

Portes, Alejandro (1976) "Determinants of the Brain Drain”, International Migration Review, 10(4): 489-508.

Sjaastad, Larry A. (1962): The costs and returns of human migration, Journal of Political Economy, 70, 4, supplement, pp. 80-93. 
Yang, Dean. 2006. "Why Do Migrants Return to Poor Countries? Evidence from Philippine Migrants' Responses to Exchange Rate Shocks.” Review of Economics and Statistics, 88(4): 715-735.

World Bank (2006) Global Economic Prospects 2006: Economic Implications of Remittances and Migration. World Bank: Washington, D.C.

World Bank (2005) Project Appraisal Document: Tonga Education Support Project, World Bank East Asia and Pacific Division, Washington D.C. 
Table 1: Tracking and Response Rates

\begin{tabular}{|c|c|c|c|c|}
\hline & $\begin{array}{c}\text { Target } \\
\text { Population }\end{array}$ & $\begin{array}{c}\text { Number with } \\
\text { Location tracked }\end{array}$ & $\begin{array}{l}\text { Number } \\
\text { Surveyed }\end{array}$ & $\begin{array}{c}\text { Survey } \\
\text { Rate }\end{array}$ \\
\hline \multicolumn{5}{|l|}{ New Zealand Top Students } \\
\hline Maths olympians & 73 & 70 & 65 & $89 \%$ \\
\hline Chemistry olympians & 48 & 47 & 43 & $90 \%$ \\
\hline Top bursary scholars & 484 & 263 & 228 & $47 \%$ \\
\hline pre-1992 Duxes & 271 & 96 & 67 & $25 \%$ \\
\hline Total New Zealand Sample & 851 & 476 & 371 & $44 \%$ \\
\hline \multicolumn{5}{|l|}{ Tongan Top Students } \\
\hline All Duxes and Proxime Accesits & 266 & 245 & 193 & $73 \%$ \\
\hline All with name known & 245 & 245 & 193 & $79 \%$ \\
\hline \multicolumn{5}{|l|}{ PNG Top Students } \\
\hline \multicolumn{5}{|l|}{ 1995-98, 2000-04 with 4.0 GPA \& } \\
\hline Booster sample of 1995-2004 Duxes & 509 & 196 & 149 & $29 \%$ \\
\hline 1976-1994 and 1999 Duxes & 182 & 102 & 87 & $48 \%$ \\
\hline Total PNG Sample & 691 & 298 & 236 & $34 \%$ \\
\hline
\end{tabular}


Table 2: The Incidence of Emigration and Return Migration

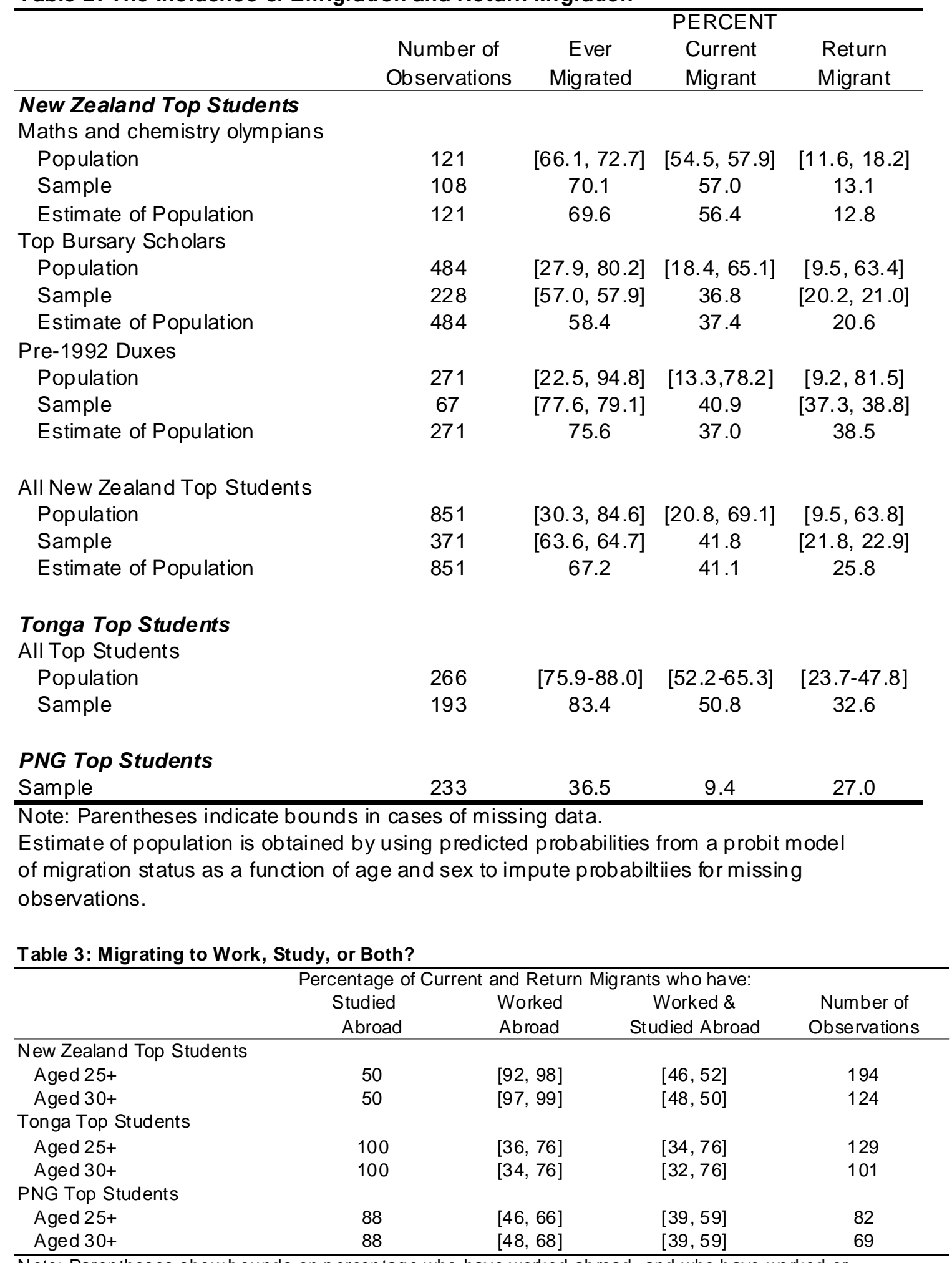

Note: Parentheses show bounds on percentage who have worked abroad, and who have worked or studied abroad. 
Table 4: Educational Attainment

\begin{tabular}{lccccc}
\hline & Law & $\begin{array}{c}\text { Percentage With } \\
\text { Medical } \\
\text { Degree }\end{array}$ & $\begin{array}{c}\text { Other } \\
\text { Masters }\end{array}$ & $\begin{array}{c}\text { Any } \\
\text { Graduate }\end{array}$ \\
$\begin{array}{l}\text { New Zealand Top Students } \\
\text { All 25+ }\end{array}$ & 30 & 7 & 12 & 19 & 64 \\
$\quad$ All 30+ & 31 & 7 & 13 & 21 & 67 \\
PNG Top Students & 4 & 5 & 7 & 14 & 29 \\
$\quad$ All 25+ & 6 & 3 & 8 & 20 & 36 \\
All 30+ & 8 & 3 & 15 & 18 & 45 \\
Tonga Top Students & 8 & 3 & 15 & 23 & 49 \\
$\quad$ All 25+ & & & & & \\
All 30+ & & & & & \\
\hline
\end{tabular}

Table 5: Migrant Status by Educational Attainment

\begin{tabular}{|c|c|c|c|}
\hline & \multicolumn{3}{|c|}{ Percentage } \\
\hline & Ever & Current & With \\
\hline & Migrated & Migrant & overseas degree \\
\hline \multicolumn{4}{|l|}{ New Zealand Top Students } \\
\hline All 25+ & 72.5 & 47.2 & 36.3 \\
\hline 25+ with PhD & $88.6^{\star \star \star}$ & $74.7^{\star \star \star}$ & $73.4^{\star \star \star}$ \\
\hline $25+$ with Medical or Law degree & 69.2 & $36.5^{\star}$ & $25.0^{*}$ \\
\hline $25+$ with any graduate degree & $79.9^{\star \star \star}$ & $55.0^{* \star *}$ & $51.8^{\star \star \star}$ \\
\hline \multicolumn{4}{|l|}{ PNG Top Students } \\
\hline All 25+ & 42.3 & 11.4 & 36.7 \\
\hline $25+$ with PhD & $100 * \star *$ & $42.9^{* \star *}$ & $100^{\star \star \star}$ \\
\hline $25+$ with Medical or Law degree & 30.4 & 4.3 & 26.1 \\
\hline $25+$ with any graduate degree & $67.8^{\star \star \star}$ & $21.4^{\star \star \star}$ & $66.1^{\star \star \star}$ \\
\hline \multicolumn{4}{|l|}{ Tonga Top Students } \\
\hline All 25+ & 87.2 & 47.3 & 85.8 \\
\hline 25+ with PhD & 100 & $72.7^{*}$ & 100 \\
\hline 25+ with Medical or Law degree & $100^{\star *}$ & 41.7 & $100^{\star \star}$ \\
\hline $25+$ with any graduate degree & 100 *** & 52.5 & $100 * \star *$ \\
\hline
\end{tabular}

Notes:

$*, * *$, and $* * *$ indicate that a t-test of difference in means shows significance relative to group without this educational level at the $10 \%, 5 \%$ and $1 \%$ levels respectively. 
Table 6: Gain in Weekly Income from Migrating

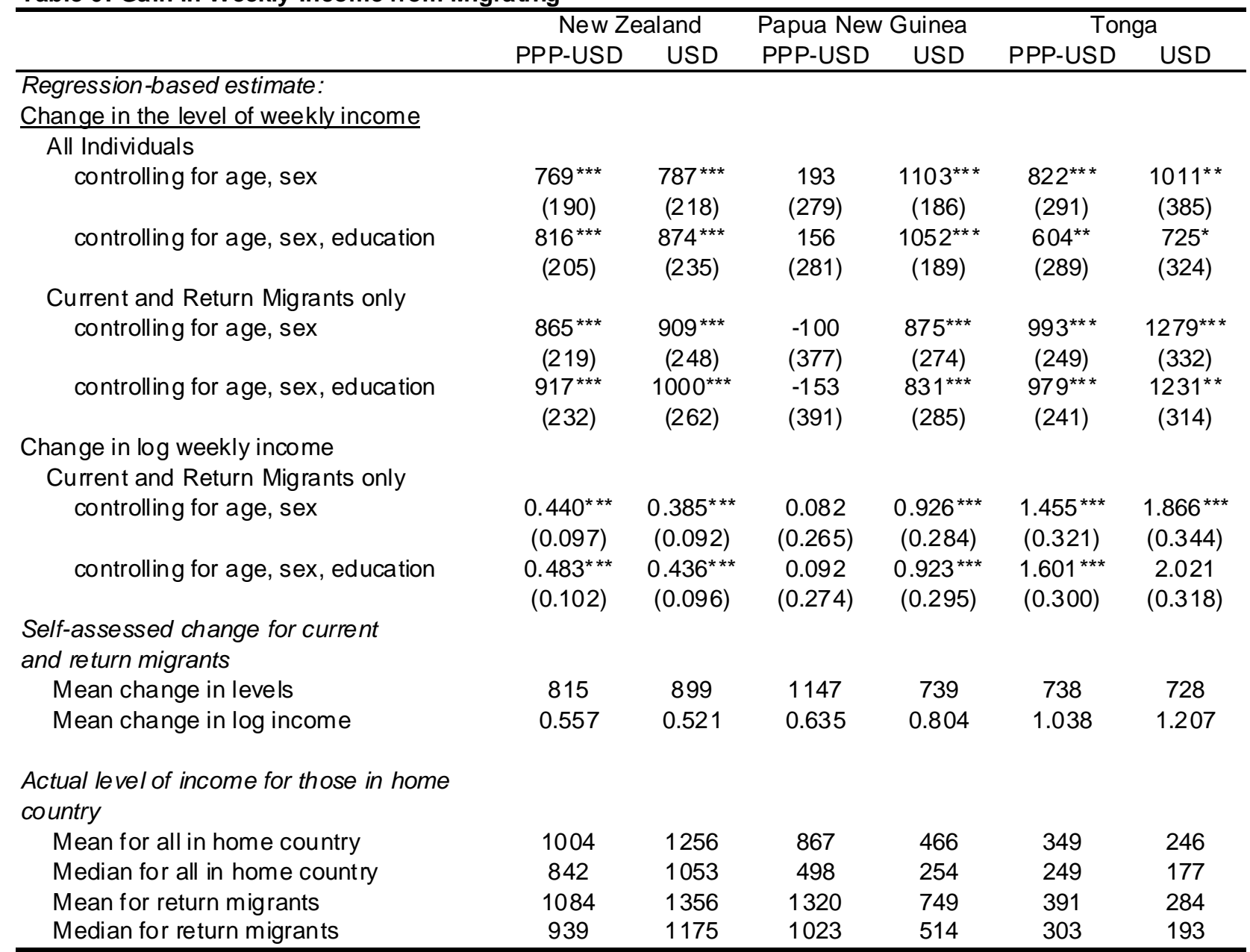
Notes:

Regression model with all individuals also contains an indicator for being a return migrant.

Education controls are dummies for having a PhD, Medical degree, Law degree, or other masters degree.

Standard errors in parentheses. *, ${ }^{*}$, and ${ }^{* \star}$ indicate significance at the $10 \%, 5 \%$ and $1 \%$ levels respectively. 
Table 7: Quantiles of Income Gain from Migrating in USD per week

\begin{tabular}{|c|c|c|c|}
\hline & New Zealand & Tonga & PNG \\
\hline \multicolumn{4}{|c|}{ Quantile Regression Estimates } \\
\hline 10th & $\begin{array}{l}222^{*} \\
(128)\end{array}$ & $\begin{array}{c}142 \\
(181)\end{array}$ & $\begin{array}{l}698^{\star \star \star} \\
(49)\end{array}$ \\
\hline 25 th & $\begin{array}{c}354^{\star \star \star} \\
(98)\end{array}$ & $\begin{array}{l}532^{\star * *} \\
(97)\end{array}$ & $\begin{array}{l}736^{\star \star *} \\
(62)\end{array}$ \\
\hline 50 th & $\begin{array}{l}508^{\star \star \star} \\
(163)\end{array}$ & $\begin{array}{l}849 * * * \\
(105)\end{array}$ & $\begin{array}{l}780^{\star \star \star} \\
(90)\end{array}$ \\
\hline 75 th & $\begin{array}{l}1086^{\star \star \star} \\
(259)\end{array}$ & $\begin{array}{l}1670^{\star \star \star} \\
(134)\end{array}$ & $\begin{array}{c}1361^{* \star *} \\
(133)\end{array}$ \\
\hline 90th & $\begin{array}{l}1511^{* *} \\
(703)\end{array}$ & $\begin{array}{l}2169^{\star} \\
(1247)\end{array}$ & $\begin{array}{c}850 \\
(530)\end{array}$ \\
\hline \multicolumn{4}{|c|}{$\begin{array}{l}\text { Self-assessed change for current } \\
\text { and return migrants }\end{array}$} \\
\hline 10th & -87 & -56 & -465 \\
\hline 25th & 193 & 80 & 147 \\
\hline 50 th & 604 & 414 & 545 \\
\hline 75 th & 1269 & 839 & 1060 \\
\hline 90th & 2156 & 1829 & 1611 \\
\hline
\end{tabular}

Standard errors in parentheses. ${ }^{*},{ }^{*}$, and ${ }^{* *}$ indicate significance at the $10 \%, 5 \%$ and $1 \%$ levels respectively. 
Table 8: What are the Determinants of Ever Migrating?

Marginal effects from probit estimation

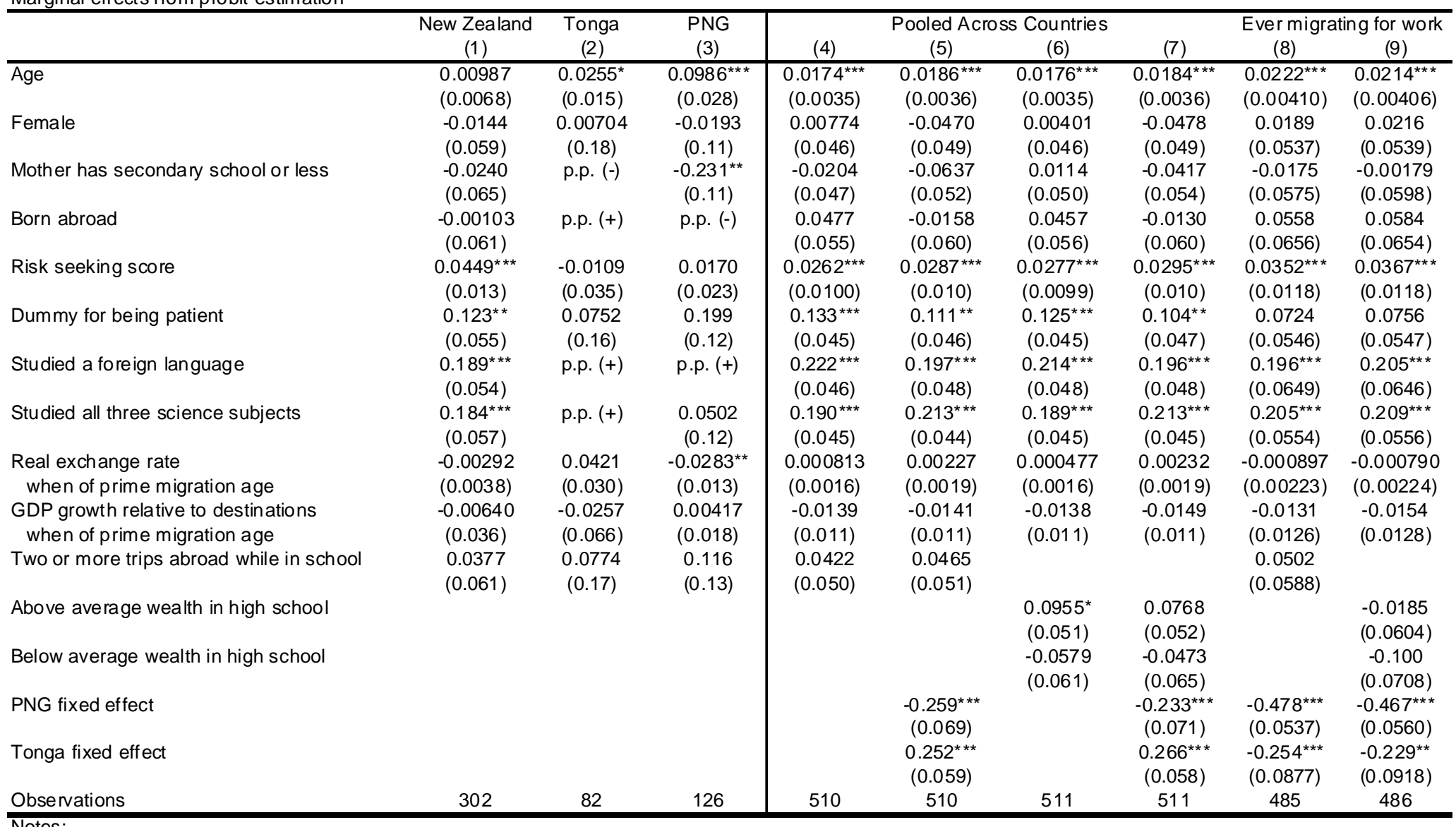

Notes:

Standard errors in parentheses *** $p<0.01,{ }^{* *} p<0.05,{ }^{*} p<0.1$

p.p. $(-)$ and p.p. $(+)$ indicate that the variable is a perfect predictor of not migrating or of migrating respectively. 
Table 9: What are the Determinants of Return Migration Among Ever Migrants? Marginal effects from Probit Estimation

\begin{tabular}{|c|c|c|c|c|c|c|c|c|c|}
\hline & $(1)$ & $(2)$ & $(3)$ & $(4)$ & $(5)$ & $(6)$ & $(7)$ & $(8)$ & $(9)$ \\
\hline Age & $\begin{array}{l}0.0124^{\star \star \star} \\
(0.0035)\end{array}$ & 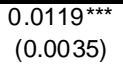 & $\begin{array}{c}0.0114^{\star \star \star} \\
(0.0039)\end{array}$ & $\begin{array}{l}0.0130^{\star \star \star} \\
(0.0035)\end{array}$ & $\begin{array}{l}0.0142^{\star \star \star} \\
(0.0035)\end{array}$ & $\begin{array}{l}0.00736 \\
(0.0047)\end{array}$ & $\begin{array}{l}0.0154^{\star \star \star} \\
(0.0037)\end{array}$ & $\begin{array}{l}0.00696^{*} \\
(0.0038)\end{array}$ & $\begin{array}{l}0.00861 \\
(0.0063)\end{array}$ \\
\hline Female & $\begin{array}{l}0.0206 \\
(0.051)\end{array}$ & $\begin{array}{l}0.0129 \\
(0.052)\end{array}$ & $\begin{array}{l}0.0274 \\
(0.057)\end{array}$ & $\begin{array}{c}-0.00751 \\
(0.052)\end{array}$ & $\begin{array}{l}0.0224 \\
(0.050)\end{array}$ & $\begin{array}{l}0.0250 \\
(0.068)\end{array}$ & $\begin{array}{l}0.0106 \\
(0.052)\end{array}$ & $\begin{array}{c}-0.0190 \\
(0.057)\end{array}$ & $\begin{array}{r}-0.0958 \\
(0.084)\end{array}$ \\
\hline Born outside country & $\begin{array}{c}-0.205^{\star \star *} \\
(0.060)\end{array}$ & $\begin{array}{c}-0.184^{\star * *} \\
(0.061)\end{array}$ & & & & & & & $\begin{array}{c}-0.0803 \\
(0.10)\end{array}$ \\
\hline Two or more trips abroad in high school & $\begin{array}{c}0.177^{\star * \star} \\
(0.058)\end{array}$ & & & & & & & & $\begin{array}{c}0.121 \\
(0.091)\end{array}$ \\
\hline Above average wealth in high school & & $\begin{array}{l}0.117^{\star} \\
(0.063)\end{array}$ & & & & & & & \\
\hline Below average wealth in high school & & $\begin{array}{l}-0.0588 \\
(0.068)\end{array}$ & & & & & & & \\
\hline Risk seeking Score & & & $\begin{array}{l}0.00543 \\
(0.013)\end{array}$ & & & & & & $\begin{array}{c}-0.00771 \\
(0.019)\end{array}$ \\
\hline Dummy for being patient & & & $\begin{array}{l}-0.0734 \\
(0.057)\end{array}$ & & & & & & $\begin{array}{l}0.0169 \\
(0.083)\end{array}$ \\
\hline Studied a foreign language & & & & $\begin{array}{l}0.0967 \\
(0.071)\end{array}$ & & & & & $\begin{array}{c}0.0918 \\
(0.12)\end{array}$ \\
\hline Studied all three science subjects & & & & $\begin{array}{c}-0.0510 \\
(0.054)\end{array}$ & & & & & $\begin{array}{r}-0.0990 \\
(0.082)\end{array}$ \\
\hline Has a PhD & & & & & $\begin{array}{l}-0.320^{* * *} \\
(0.055)\end{array}$ & & & & $\begin{array}{c}-0.257^{\star * *} \\
(0.087)\end{array}$ \\
\hline Has a Medical or Law Degree & & & & & $\begin{array}{l}0.0923 \\
(0.067)\end{array}$ & & & & $\begin{array}{c}0.0808 \\
(0.11)\end{array}$ \\
\hline Has another form of Masters Degree & & & & & $\begin{array}{l}-0.0607 \\
(0.062)\end{array}$ & & & & $\begin{array}{r}-0.0613 \\
(0.091)\end{array}$ \\
\hline Change in log income expected from migration & & & & & & $\begin{array}{l}-0.0194 \\
(0.031)\end{array}$ & & & $\begin{array}{r}-0.0407 \\
(0.039)\end{array}$ \\
\hline Has a parent alive in the ir home country & & & & & & & $\begin{array}{l}0.231^{\star * *} \\
(0.065)\end{array}$ & & $\begin{array}{l}0.203^{* *} \\
(0.096)\end{array}$ \\
\hline Has a spouse who is a citizen of another country & & & & & & & $\begin{array}{c}-0.267^{\star \star *} \\
(0.056)\end{array}$ & & $\begin{array}{c}-0.150 \\
(0.098)\end{array}$ \\
\hline Extent to which salaries draw them abroad & & & & & & & & $\begin{array}{r}-0.0327 \\
(0.033)\end{array}$ & $\begin{array}{r}-0.0451 \\
(0.045)\end{array}$ \\
\hline Extent to which lifestyle draw them abroad & & & & & & & & $\begin{array}{c}-0.0630^{* * *} \\
(0.022)\end{array}$ & $\begin{array}{c}-0.0597^{*} \\
(0.031)\end{array}$ \\
\hline Extent to which career draws them abroad & & & & & & & & $\begin{array}{c}-0.0411 \\
(0.036)\end{array}$ & $\begin{array}{r}-0.0446 \\
(0.051)\end{array}$ \\
\hline NZ dummy^Extent to which career draws abroad & & & & & & & & $\begin{array}{c}-0.187^{* * *} \\
(0.048)\end{array}$ & $\begin{array}{c}-0.174^{\star * *} \\
(0.065)\end{array}$ \\
\hline Mother has less than secondary education & & & & & & & & & $\begin{array}{l}0.0667 \\
(0.088)\end{array}$ \\
\hline PNG country effect & $\begin{array}{l}0.266^{* * *} \\
(0.071)\end{array}$ & $\begin{array}{l}0.319 * \star \star \\
(0.072)\end{array}$ & $\begin{array}{l}0.338^{* \star *} \\
(0.072)\end{array}$ & $\begin{array}{l}0.359 * \star * \\
(0.066)\end{array}$ & $\begin{array}{l}0.277^{\star \star *} \\
(0.069)\end{array}$ & $\begin{array}{l}0.350^{\star * *} \\
(0.078)\end{array}$ & $\begin{array}{l}0.306^{\star \star *} \\
(0.070)\end{array}$ & $\begin{array}{l}0.242^{\star \star *} \\
(0.090)\end{array}$ & $\begin{array}{l}0.257^{*} \\
(0.15)\end{array}$ \\
\hline Tonga country effect & $\begin{array}{c}-0.0336 \\
(0.059)\end{array}$ & $\begin{array}{l}0.0115 \\
(0.065)\end{array}$ & $\begin{array}{c}0.0154 \\
(0.068)\end{array}$ & $\begin{array}{l}0.0513 \\
(0.065)\end{array}$ & $\begin{array}{c}-0.0461 \\
(0.057)\end{array}$ & $\begin{array}{l}0.214^{\star *} \\
(0.092)\end{array}$ & $\begin{array}{c}-0.0103 \\
(0.061)\end{array}$ & $\begin{array}{l}-0.105 \\
(0.075)\end{array}$ & $\begin{array}{c}0.00584 \\
(0.14)\end{array}$ \\
\hline Observations & 427 & 425 & 358 & 425 & 461 & 253 & 419 & 391 & 218 \\
\hline
\end{tabular}

Standard errors in parentheses ${ }^{* *} p<0.01,{ }^{* *} p<0.05,{ }^{*} p<0.1$ 
Figure 1

New Zealand Top Students: Migrant Status by Age

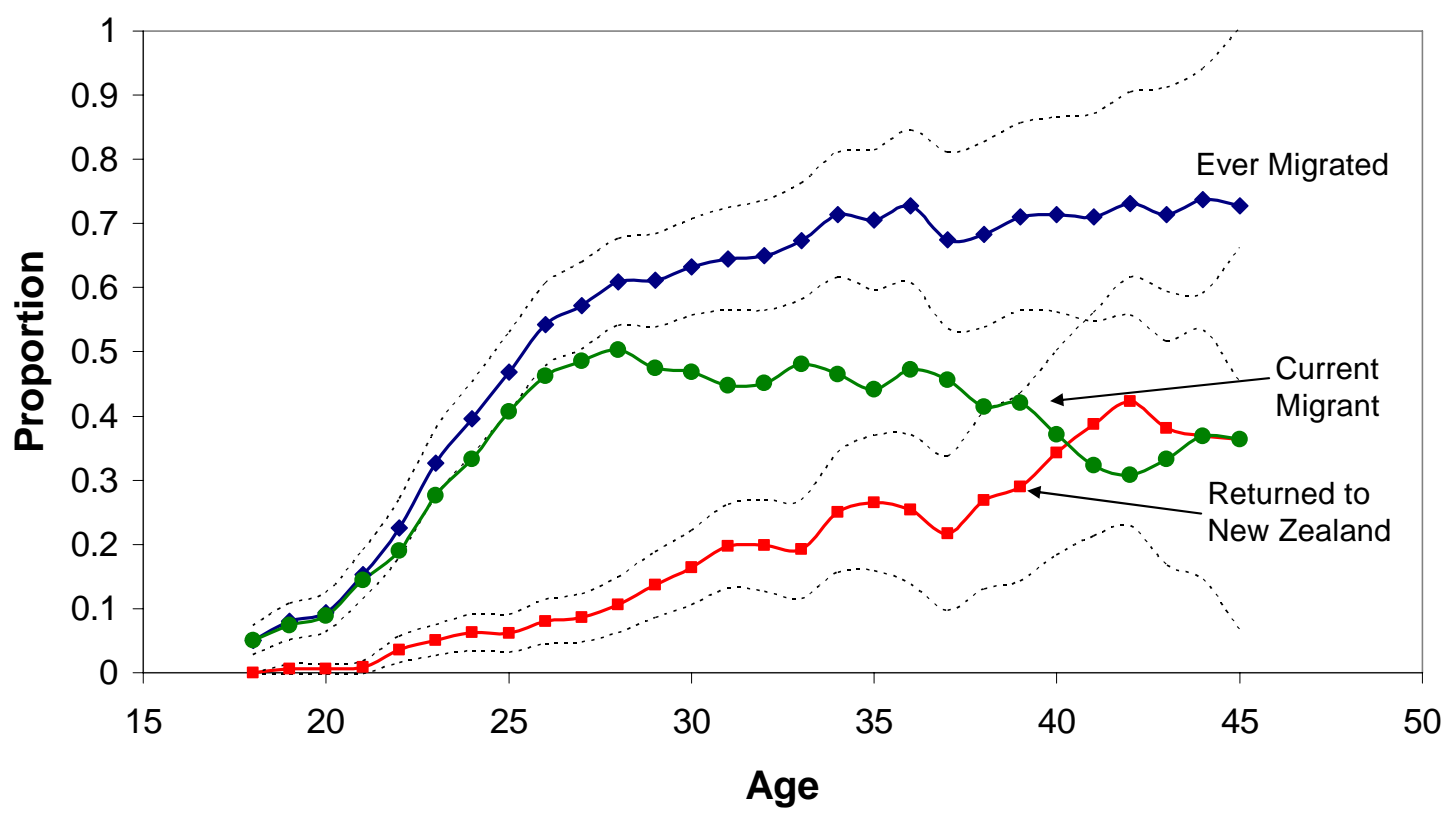

Figure 2

Tongan Top Students: Migrant Status by Age

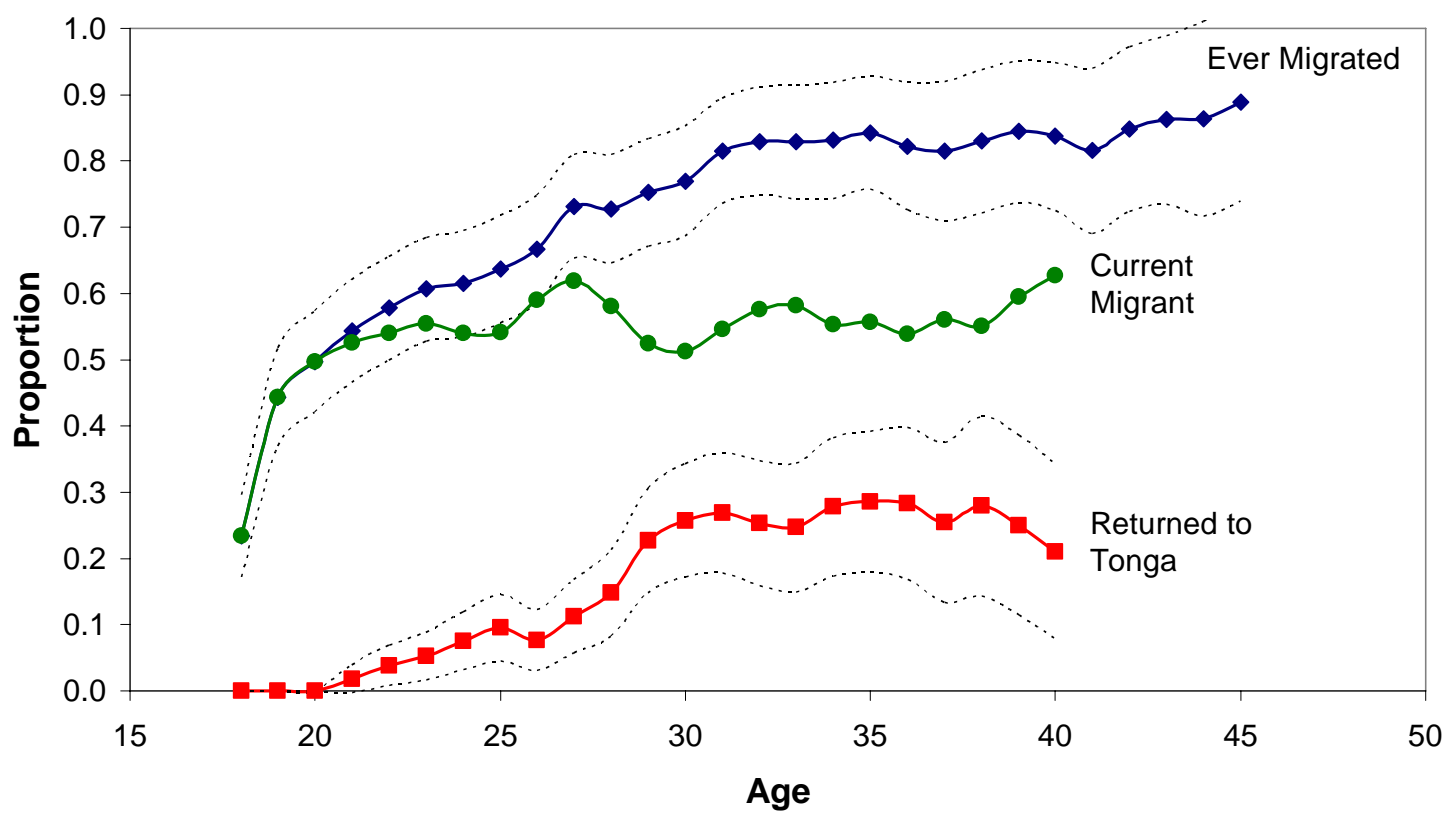


Figure 3:

PNG Top Students: Migrant Status by Age

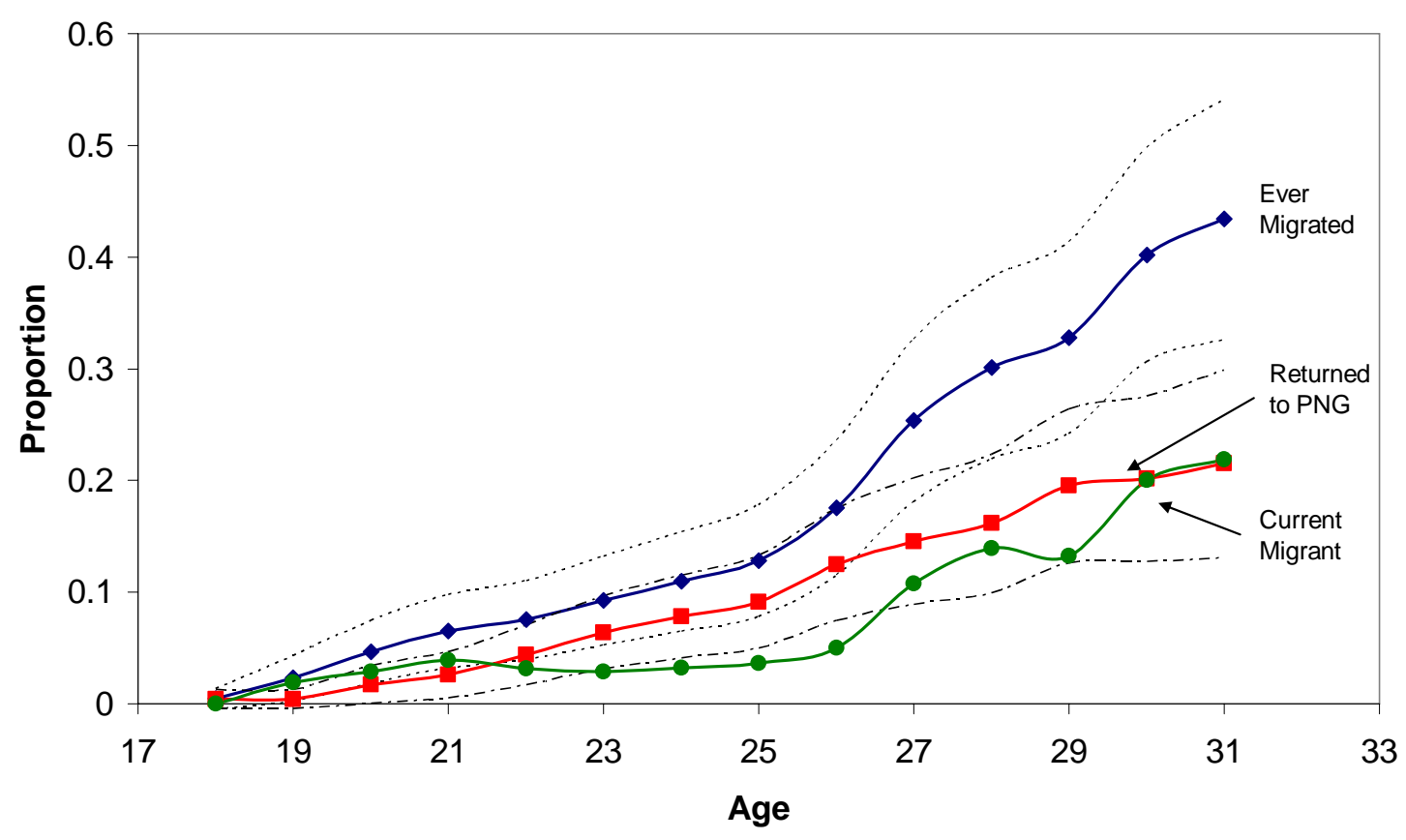

Figure 4a: Cohort Effects in Ever Migrating - New Zealand Top Students

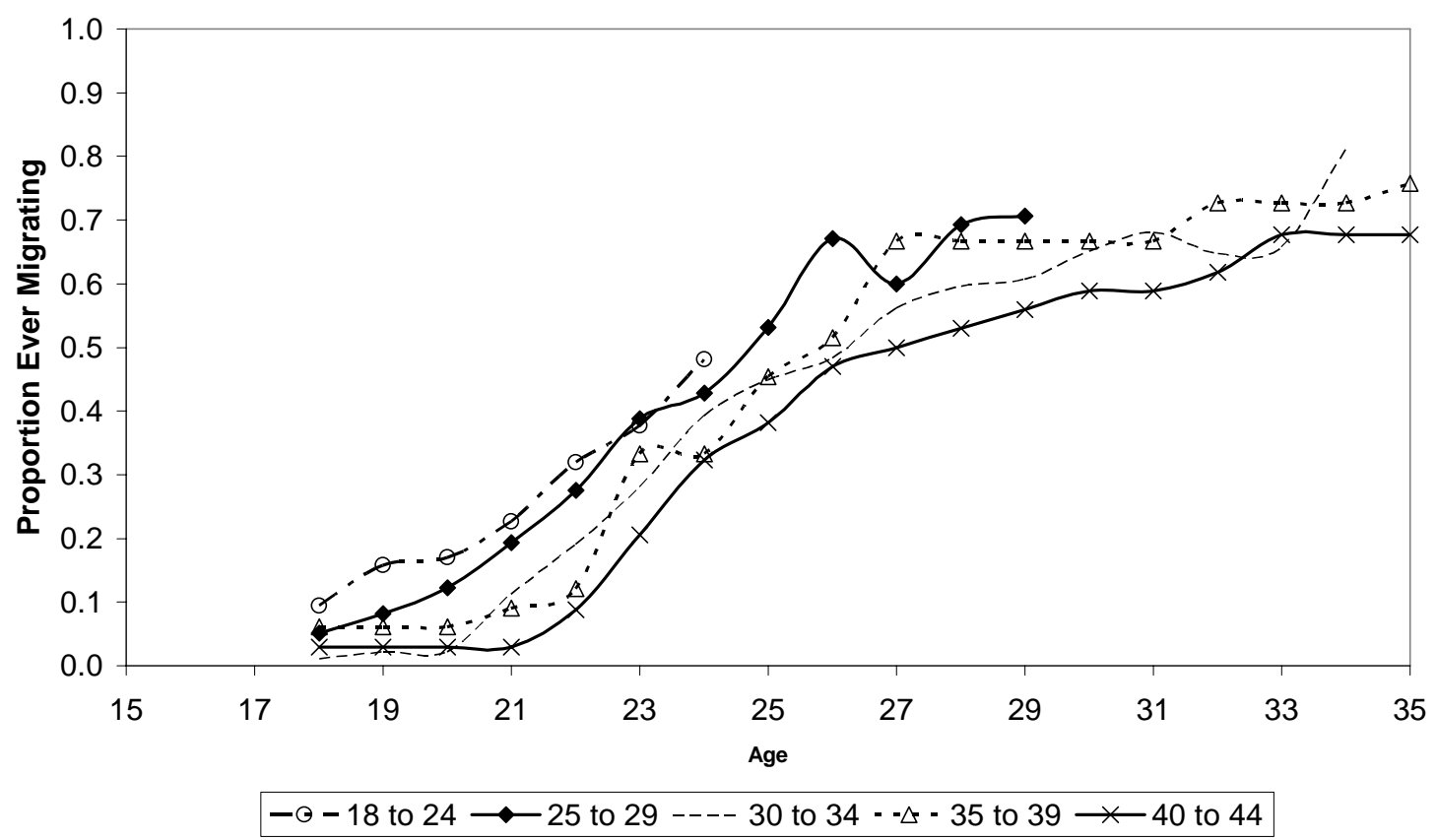


Figure 4b: Cohort Effects in Ever Migrating - Tongan Top Students

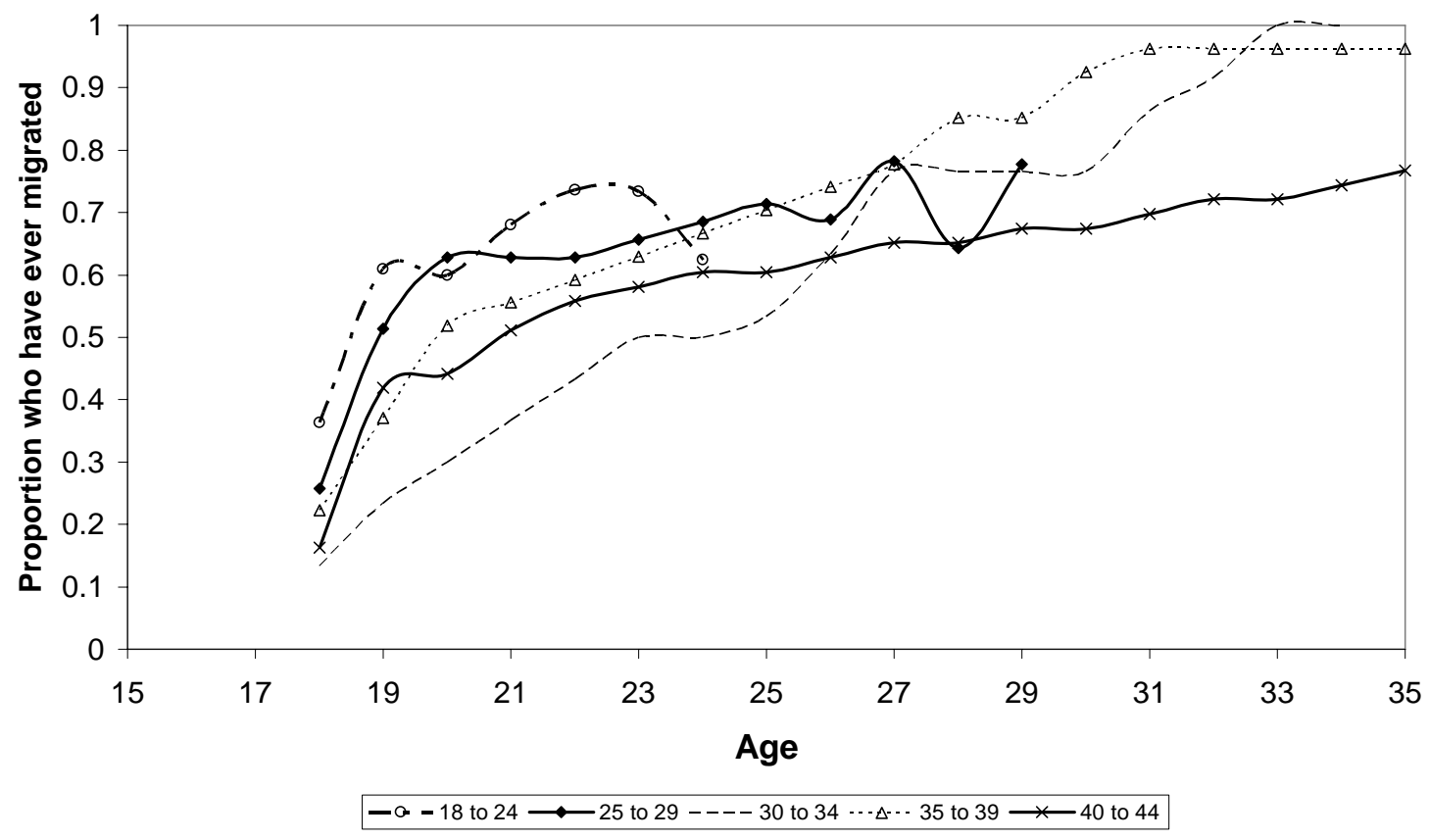

Figure 4c: Cohort Effects in Ever Migrating - PNG Top Students

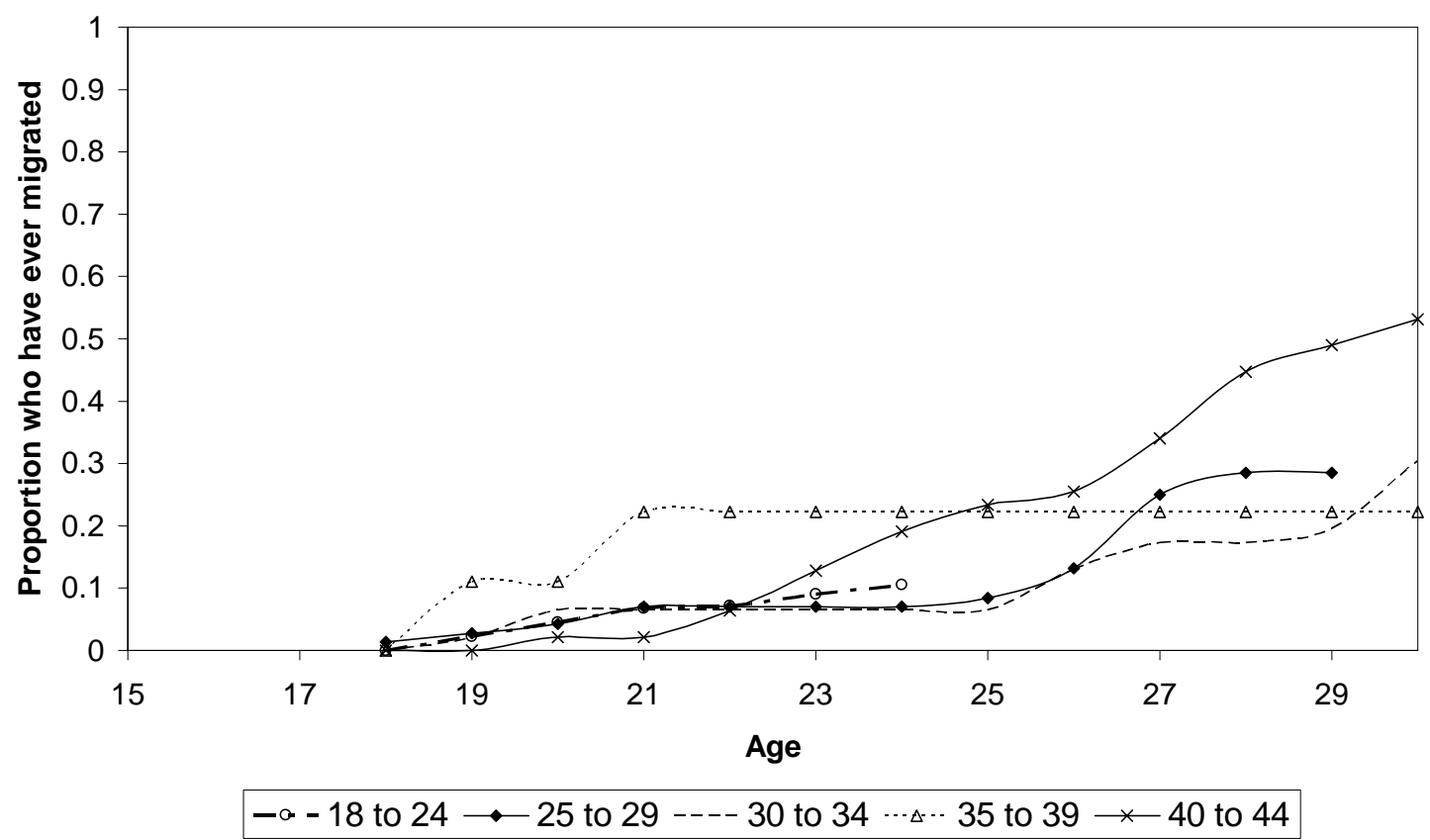


Figure 5: Push-Pull Factors for New Zealand Top Students - Panel A

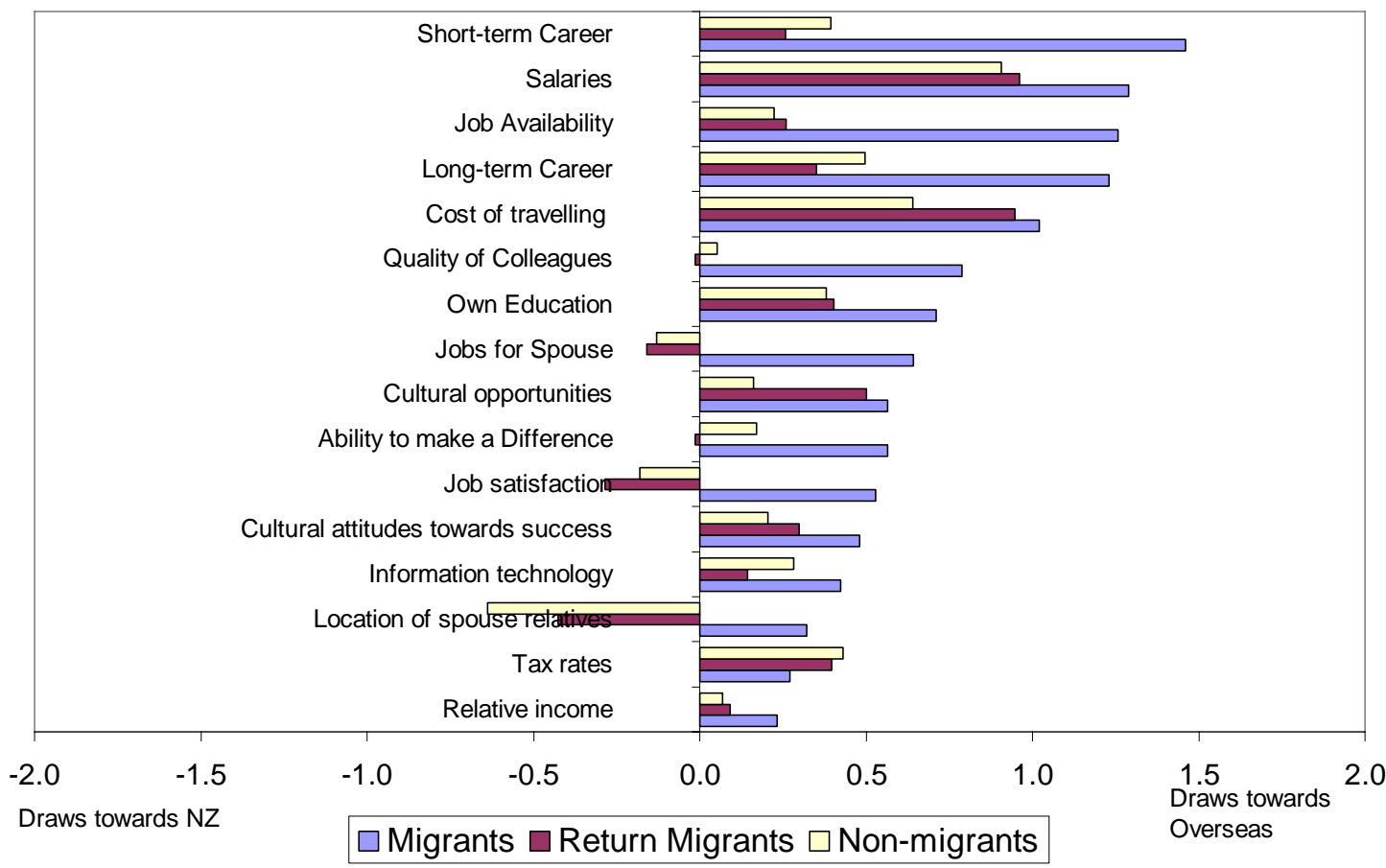

Figure 5: Push-Pull Factors for New Zealand Top Students - Panel B

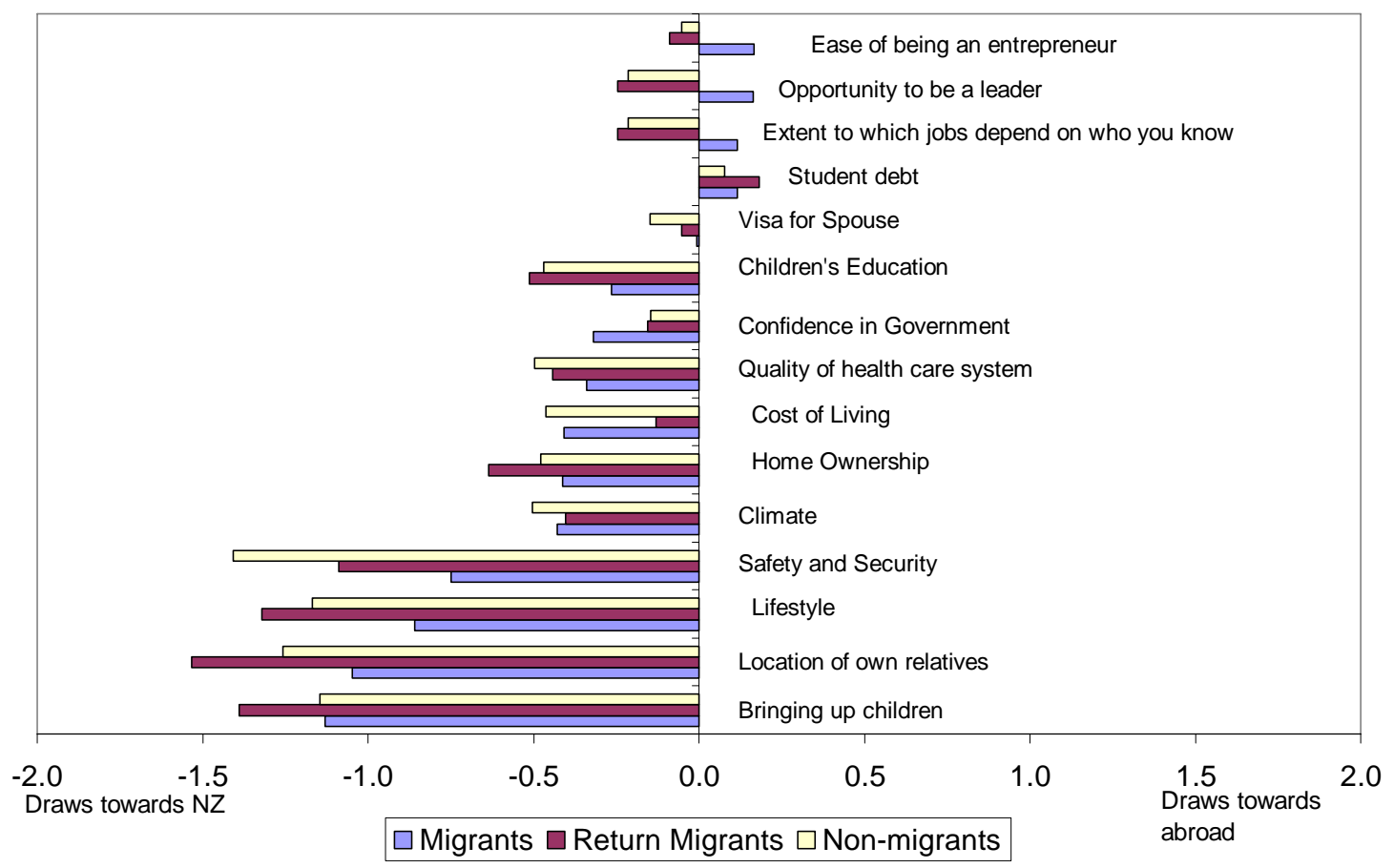


Figure 6: Push-Pull Factors for PNG Top Students - Panel A

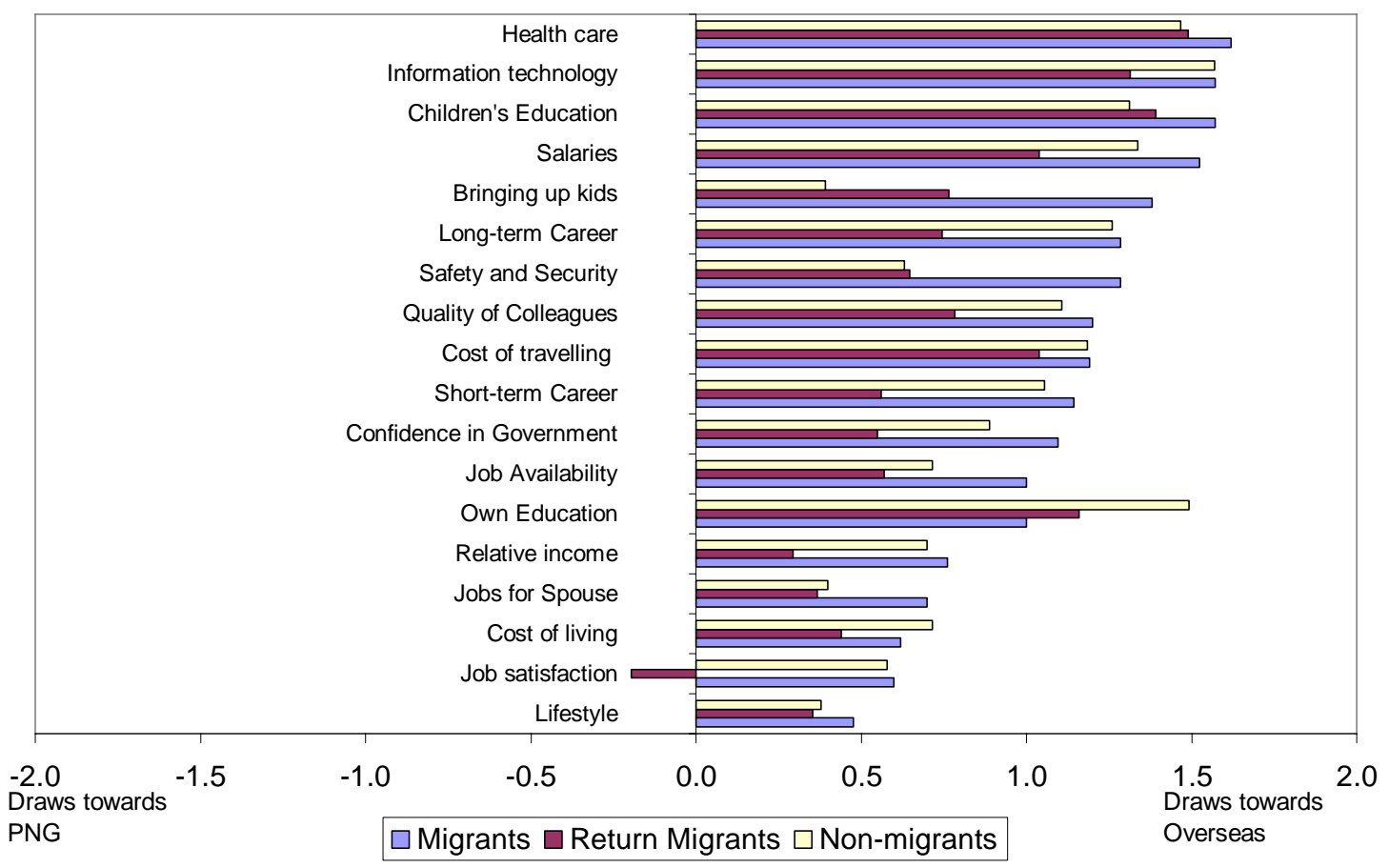

Figure 6: Push-Pull Factors for PNG Top Students - Panel B

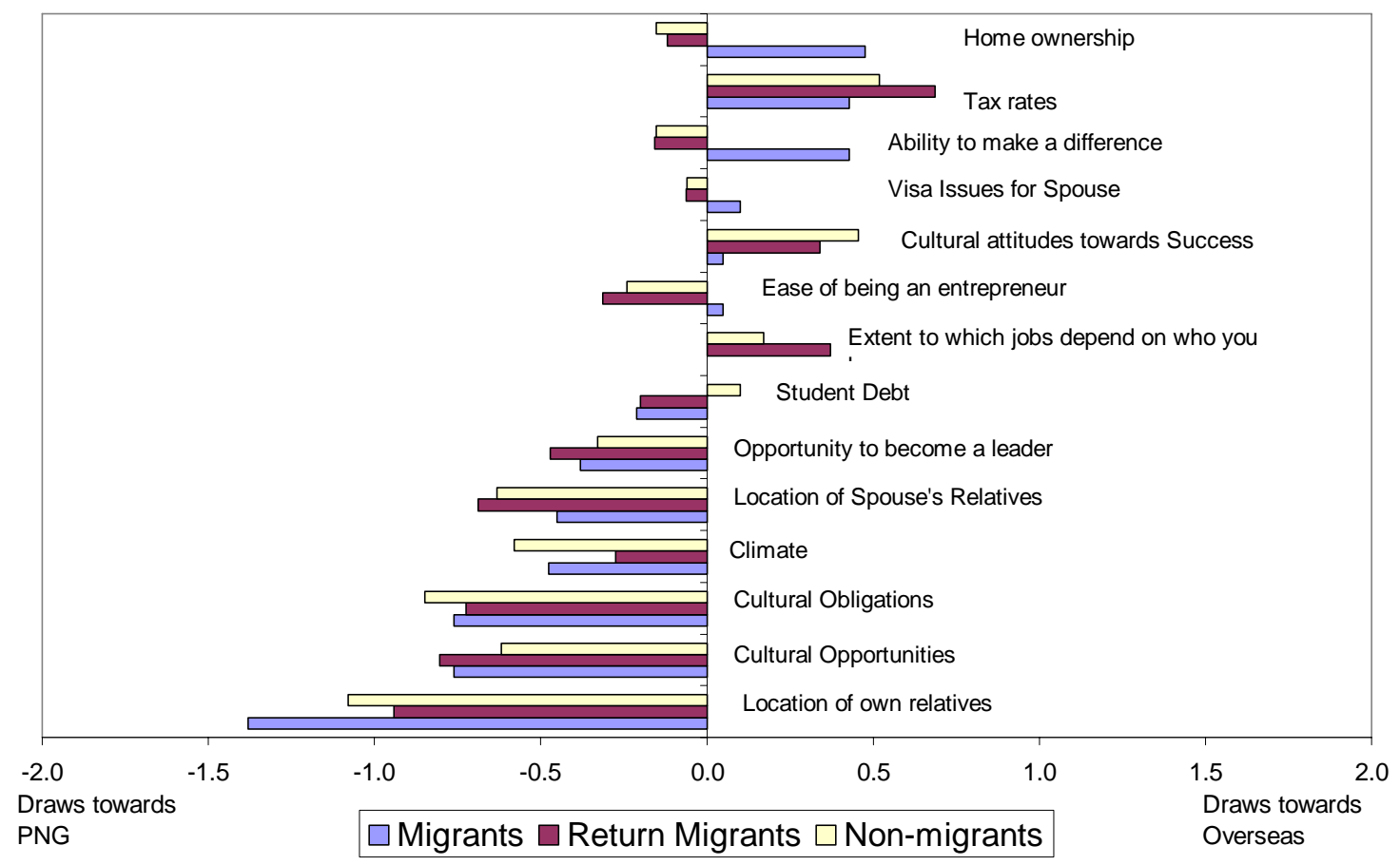


Figure 7: Push-Pull Factors for Tongan Top Students - Panel A

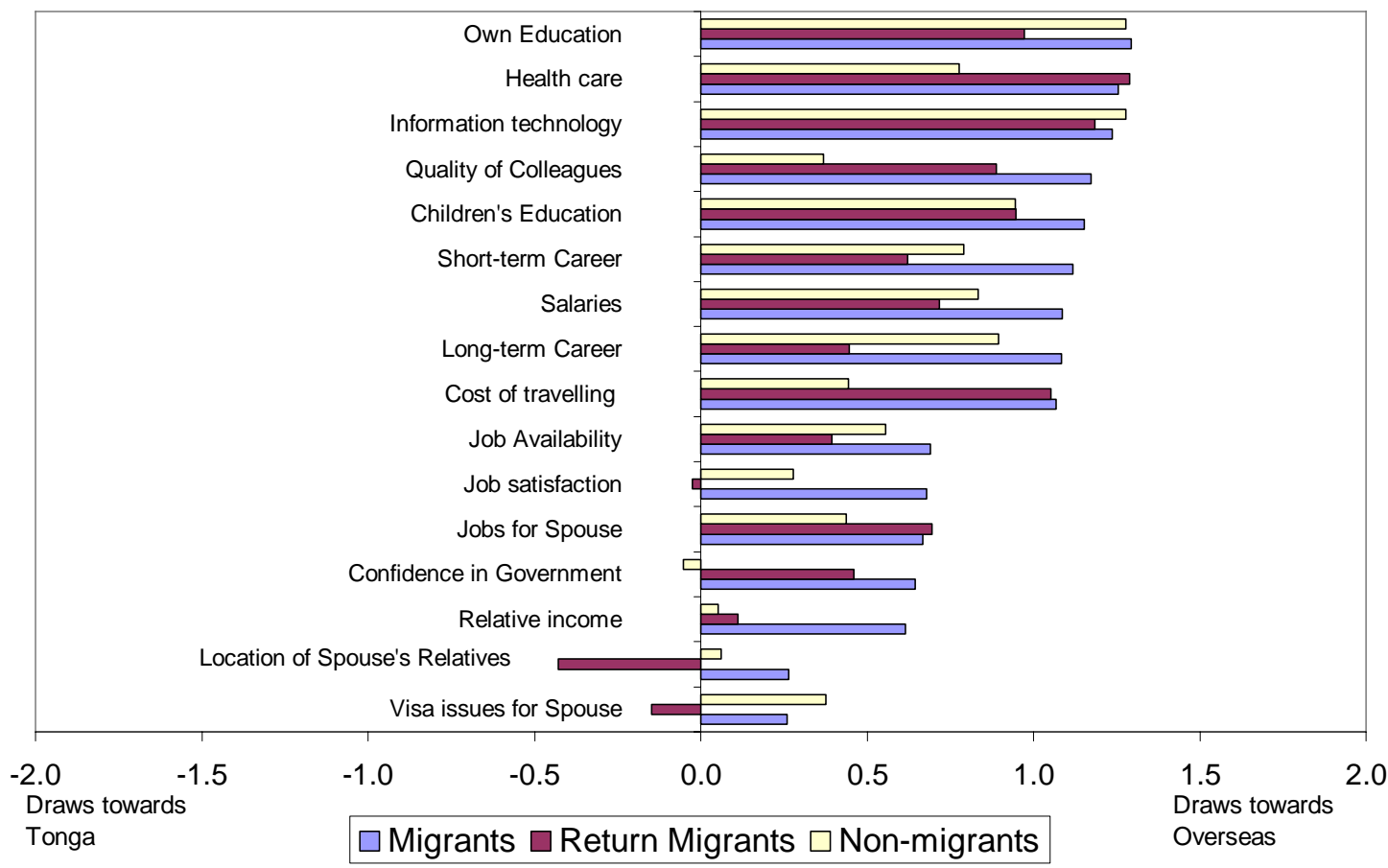

Figure 7: Push-Pull Factors for Tongan Top Students: Panel B

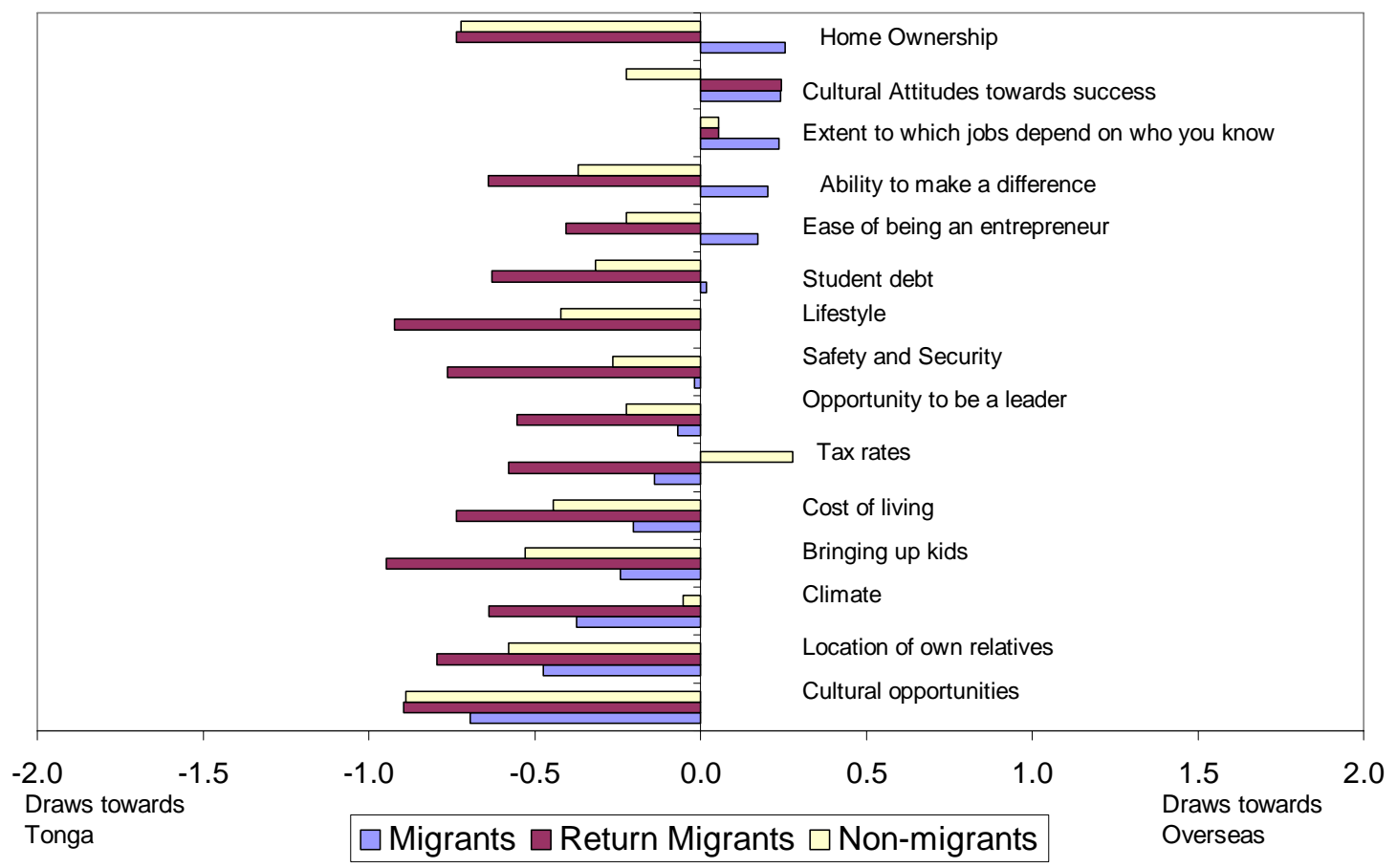

